\title{
Study on the strength of glued laminated timber beams with round holes: proposal of the design formula for the splitting strength
}

\author{
Shigefumi Okamoto ${ }^{1 *}$ (D), Nobuhiko Akiyama ${ }^{2}$, Yasuhiro Araki ${ }^{2}$, Kenji Aoki ${ }^{3}$ and Masahiro Inayama ${ }^{3}$
}

\begin{abstract}
When a glued laminated timber (GLT) beam with a round hole is subjected to a shear force and bending moment, the hole will crack and fail due to a large tensile stress perpendicular to the grain and shear stresses. If the stresses acting on the hole are known, it is possible to estimate the fracture load. However, it is necessary to obtain the stresses acting on the hole by finite element analysis, which is very time consuming. In this study, to easily estimate the fracture load, we proposed a formula to estimate the bearing capacity at the time of a hole fracture by obtaining the stress acting on the hole through finite element analysis and an approximate formula. The validity of the proposed formula was verified using the existing experimental data of a GLT beam. As a result, it was confirmed that the proposed equation can estimate the fracture load of GLT beams in Japan and that the proposed equation can estimate the fracture load of GLT beams in countries other than Japan with some accuracy.
\end{abstract}

Keywords: Glued laminated timber, Beam, Round hole, Splitting, Finite element method

\section{Introduction}

When a glued laminated timber (GLT) beam with a round hole is affected by a shear force or bending moment, a large tensile stress perpendicular to the grain acts on the cracking plane, and the tensile stress decreases exponentially with the distance from the hole (Fig. 1). Since the shear force and bending moment act at the same time, a crack occurs in the range of $\theta=45^{\circ}$ to $60^{\circ}$ in Fig. 1, where the tensile stress perpendicular to the grain is the maximum tensile stress. When there is a stress gradient, as shown in Fig. 1, it is difficult to estimate the bearing capacity at the moment of split fracture based on material mechanics. Therefore, a mean stress method (a generalization of linear elastic fracture mechanics, as shown in Fig. 2) applicable to beams with notches or holes has been proposed [1]. However, the mean stress method has a problem associated with overestimating the bearing capacity at fracture when the hole is very small or large. Therefore, the authors proposed Eqs. (1) and (2), which take the size effect into account in the mean stress method. Equations (1) and (2) were validated against GLT beams of Scots pine and Japanese larch specified in the Japanese Agricultural Standard (JAS) [2-4]:

$$
\begin{aligned}
& \max \left\{\sqrt{\left(\bar{\sigma} / F_{t 90}\right)^{2}+\left(\bar{\tau} / F_{s}\right)^{2}}\right\} \leq k_{\mathrm{vol}}, \\
& k_{\mathrm{vol}}=\left(\frac{30}{\max (0.2 D, 30)}\right)^{0.14}, \\
& x=\frac{a_{\mathrm{ms}}}{1+\frac{a_{\mathrm{ms}}}{\alpha \cdot D}}
\end{aligned}
$$

\footnotetext{
*Correspondence: okamoto@osaka-cu.ac.jp

${ }^{1}$ Graduate School of Human Life Science, Osaka City University, 3-3-138

Sugimoto, Sumiyoshi-ku, Osaka 558-8585, Japan

Full list of author information is available at the end of the article
}

\section{Springer Open}

(C) The Author(s) 2022. Open Access This article is licensed under a Creative Commons Attribution 4.0 International License, which permits use, sharing, adaptation, distribution and reproduction in any medium or format, as long as you give appropriate credit to the original author(s) and the source, provide a link to the Creative Commons licence, and indicate if changes were made. The images or other third party material in this article are included in the article's Creative Commons licence, unless indicated otherwise in a credit line to the material. If material is not included in the article's Creative Commons licence and your intended use is not permitted by statutory regulation or exceeds the permitted use, you will need to obtain permission directly from the copyright holder. To view a copy of this licence, visit http://creativecommons.org/licenses/by/4.0/. 

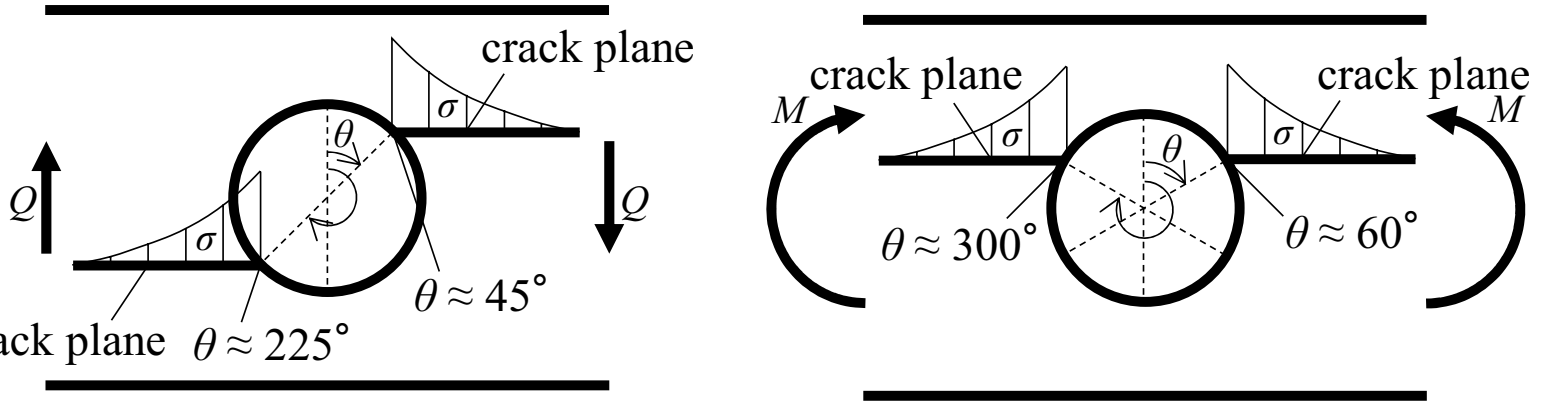

Pure shear force (center of the hole)

Pure bending moment

Fig. 1 Distribution of the tensile stress perpendicular to the grain in the highest stress zone around the hole

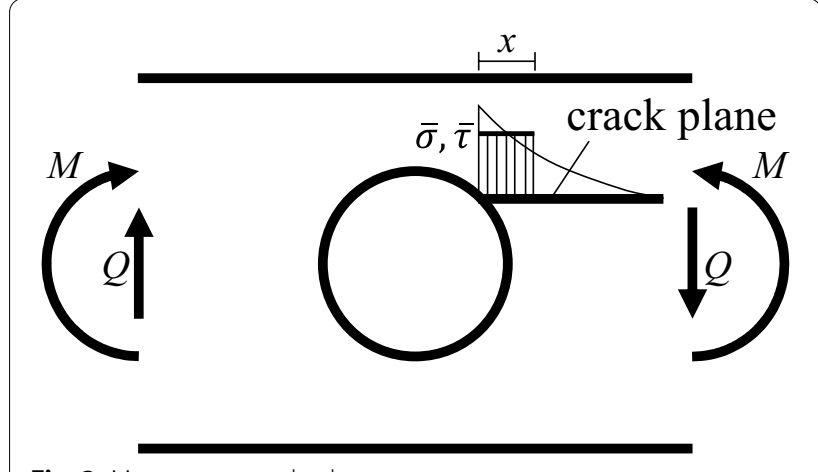

Fig. 2 Mean stress method

$$
a_{\mathrm{ms}}=\frac{2}{\pi} \cdot \frac{G_{\mathrm{I} c}}{F_{t 90}^{2}} \cdot \sqrt{\frac{2 \cdot E_{x} \cdot E_{y}}{\sqrt{\frac{E_{x}}{E_{y}}} \cdot \frac{E_{x}}{2 \cdot G_{x y}}-v_{x y} \cdot \frac{E_{x}}{E_{y}}}}
$$

where $D$ is the diameter of the hole, $F_{t 90}$ is the tensile strength perpendicular to the grain, $F_{s}$ is the shear strength, $\bar{\sigma}$ and $\bar{\tau}$ are the mean values of the tensile stress $\sigma$ and the shear stress $\tau$ perpendicular to the grain in the potential fracture area of length $x$ (Fig. 2), $k_{\text {vol }}$ is the factor of the size effect, $G_{\mathrm{I} c}$ is the mode I fracture energy, $E_{x}$ is the modulus of elasticity parallel to the grain, $E_{y}$ is the Young's modulus perpendicular to the grain, $G_{x y}$ is the shear modulus, $v_{x y}$ is the Poisson's ratio, $\alpha$ is a constant (if the hole is small, $\alpha=1$ [3] and for $D / H \leq 0.5, \alpha=1$ because the shape of the stress distribution is the same), and $H$ is the beam height. Since $\bar{\sigma}$ is the dominant stress at fracture, $a_{\mathrm{ms}}$ is set to the value of pure mode I.

Equations (1) and (2) can be used to estimate the bearing capacity of a hole at the time of fracture, but this is very time consuming because the stresses acting around the hole must be determined by finite element analysis (FEA). Therefore, in this study, the maximum stress acting around the hole and the maximum value of the average stress over a certain length were formulated using FEA. Then, a simple calculation formula was proposed to estimate the bearing capacity at the time of a hole fracture. The validity of the formula was verified using existing experimental data. However, in the design code for laminated wood with round holes, the maximum value of the hole diameter $(D)$ /beam height $(H)$ is 0.5 at most [5], so $D / H \leq 0.5$ is selected as the applicable range.

\section{Materials and methods}

Finite element analysis

The stresses acting on the holes in the beam were determined by two types of two-dimensional finite element analysis (2D-FEA), "analysis of stress around the hole" and "analysis of the stress distribution in the direction parallel to the grain". The stresses acting on the holes in the beam were determined by 2D-FEA using ANSYS 18.2. The specification of the 2D-FEA was a case where only the shear force or bending moment acts on the center of the hole with $D / H$ as a variable. Then, an approximate expression for the average stress for Eq. (1) was derived from the stresses obtained by the 2D-FEA. The details of the 2D-FEA are described below.

The numerical finite element (FE) model was set up for a case where the stress at the center of the hole was shear force only $\left(Q=\mathrm{\tau}_{1} B H(\mathrm{~N}), M=0\right.$, and $\left.\tau_{1}=1 \mathrm{~N} / \mathrm{mm}^{2}\right)$ and bending moment only $\left(Q=0, M=\tau_{1} B H^{2}(\mathrm{~N} \mathrm{~mm})\right.$, and $\tau_{1}=1 \mathrm{~N} / \mathrm{mm}^{2}$ ), as shown in Fig. 3. "Edge and node parallel to the grain" is the edge and node provided to obtain the stress distribution in the direction parallel to the grain. "Edge and node parallel to the grain" is not placed in "analysis of stress around the hole", but "edge and node parallel to the grain" is placed in "analysis of stress distribution in the direction parallel to the grain". "Edges and nodes parallel to the grain" were located every $0.01 \mathrm{D}$ in 


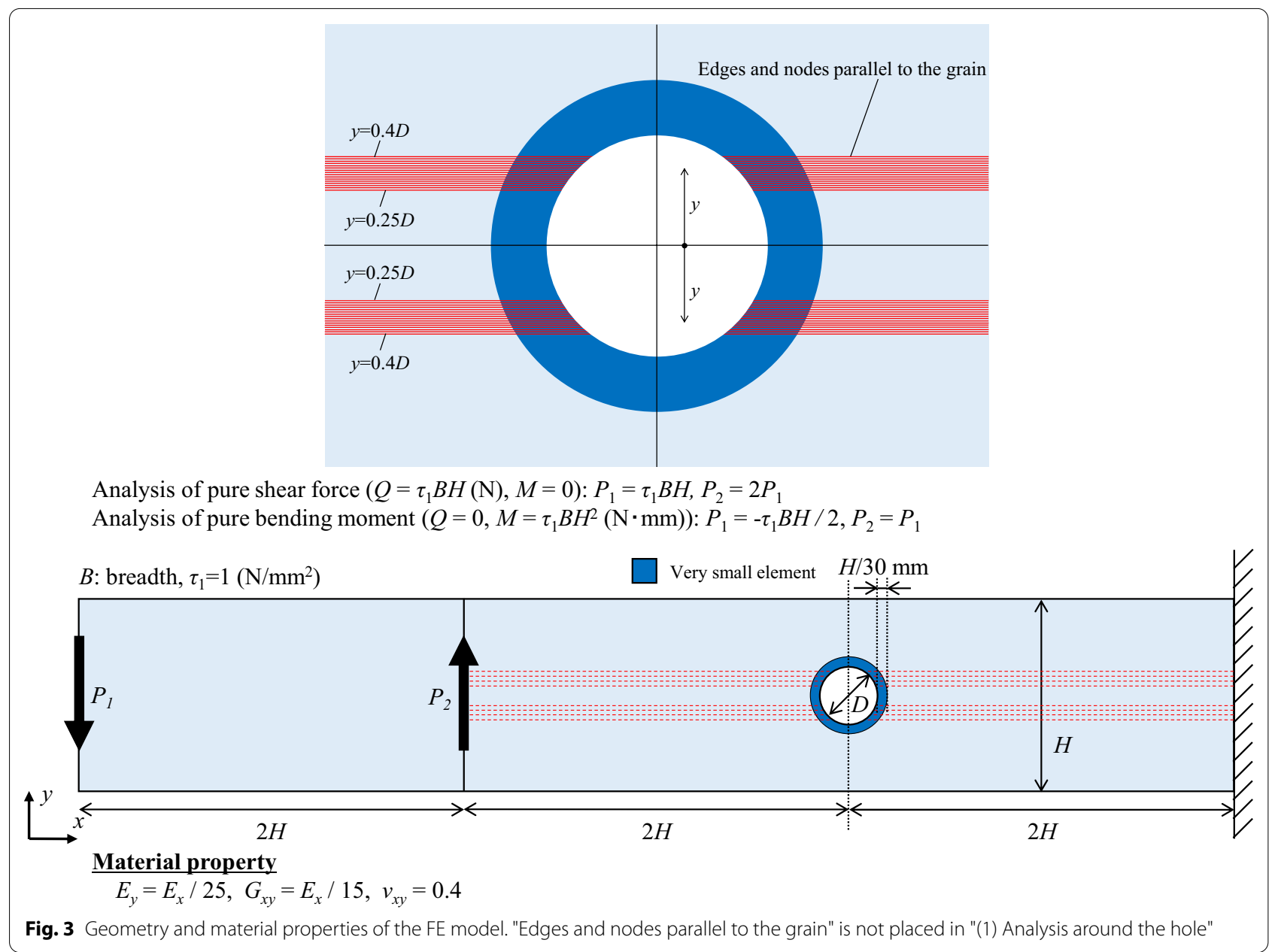

the range of $y=0.25 D$ (at $\theta=60^{\circ}$ in Fig. 1) to $y=0.4 D$ (at $\theta=36.9^{\circ}$ in Fig. 1) perpendicular to the grain (y-direction) from the center of the hole. The $D / H$ values were set to $0.05,0.1,0.2,0.3,0.4$, and 0.5 . However, analysis of $D / H$ values of $0.6,0.7,0.8$, and 0.9 was also performed for reference only in "analysis of stress around the hole". Since the stresses around the hole when the shear force of $Q=\tau_{1} B H(\mathrm{~N})$ or the bending moment of $M=\tau_{1} B H^{2}$ $(\mathrm{N} \mathrm{mm})$ acts on the beam are the same even if the beam height $H$ is different, $H=300 \mathrm{~mm}$ was used. The material parameters of the elements were determined in the same way as in $[3,4]$. The results are the same even if the value of the Young's modulus $E_{x}$ in the fiber direction is different, but for the time being, $E_{x}=10,000 \mathrm{~N} / \mathrm{mm}^{2}$ was used. The Young's modulus perpendicular to the grain was set to $E_{y}=E_{x} / 25$, the shear modulus was set to $G_{x y}=E_{x} / 15$, and the Poisson's ratio was set to $v_{x y}=0.4$. The wood was treated as a four-node planar element, and the elements were less than $5 \mathrm{~mm}(H / 60)$. The range of $10 \mathrm{~mm}$
$(H / 30)$ from the hole was divided into small sections so that the nodes were placed at less than one degree. The mesh size of the FE model for "analysis of stress around the hole" is shown in Additional file 1: Fig. S1. The mesh size of the FE model for "analysis of the stress distribution in the direction parallel to the grain" is shown in Additional file 1: Fig. S2. The elements were very finely divided around only the hole, so some 3-node planar elements were placed. For the numerical FE results, when all the elements were reduced in size and the number of elements was doubled, the error in the stress around the holes was less than $1 \%$, so we concluded that the optimal solution could be obtained by the element division shown in Additional file 1: Figs. S1 and S2.

\section{Experimental data for beams with round holes}

The existing experimental data [3, 4, 6-13] of a GLT beam with only one round hole with $D / H \leq 0.5$ in the center were used to verify the validity of a simple calculation formula to estimate the bearing capacity at the time 
Table 1 Experimental data of GLT beams with round holes in Japan

\begin{tabular}{|c|c|c|c|c|c|c|c|c|c|c|}
\hline Test series & Tree species & Strength class & $\frac{\text { Density }}{\left(\mathrm{kg} / \mathrm{m}^{3}\right)}$ & $\begin{array}{l}B \\
(\mathrm{~mm})\end{array}$ & $\begin{array}{l}H \\
(\mathrm{~mm})\end{array}$ & $\begin{array}{l}D \\
(\mathrm{~mm})\end{array}$ & $D / H$ & $M /(Q H)$ & $\frac{Q_{\mathrm{Ini}}}{(\mathrm{kN})}$ & $\begin{array}{l}Q_{\max } \\
(k N)\end{array}$ \\
\hline \multirow[t]{23}{*}{ OKAa [3] } & Scots pine & E105-F300 & - & 105 & 150 & 30 & 0.20 & 2.33 & 40.3 & 53.5 \\
\hline & & & & & & & & & 39.7 & 57.5 \\
\hline & & & & & & & & & 36.8 & 56.1 \\
\hline & & & & & & 50 & 0.33 & 2.33 & 40.2 & 46.2 \\
\hline & & & & & & & & & 37.6 & 43.5 \\
\hline & & & & & & & & & 40.1 & 42.2 \\
\hline & & & & & 300 & 30 & 0.10 & 2.33 & 68.0 & 102.4 \\
\hline & & & & & & & & & 69.1 & 93.4 \\
\hline & & & & & & 60 & 0.20 & 2.33 & 67.1 & 81.9 \\
\hline & & & & & & & & & 68.7 & 90.2 \\
\hline & & & & & & & & & 63.2 & 89.7 \\
\hline & & & & & & 100 & 0.33 & 2.33 & 67.1 & 74.4 \\
\hline & & & & & & & & & 63.3 & 80.2 \\
\hline & & & & & & & & & 66.6 & 83.9 \\
\hline & & & & & 450 & 90 & 0.20 & 2.33 & 88.3 & 135.1 \\
\hline & & & & & & & & & 99.4 & 139.2 \\
\hline & & & & & & & & & 85.9 & 114.1 \\
\hline & & & & & & 150 & 0.33 & 2.33 & 76.4 & 108.5 \\
\hline & & & & & & & & & 91.8 & 99.0 \\
\hline & & & & & & & & & 87.7 & 112.0 \\
\hline & & & & & 750 & 250 & 0.33 & 2.33 & 109.0 & 139.4 \\
\hline & & & & & & & & & 98.2 & 120.1 \\
\hline & & & & & & & & & 87.1 & 124.3 \\
\hline \multirow[t]{20}{*}{ OKAb [3] } & Japanese larch & E105-F300 & - & 105 & 150 & 30 & 0.20 & 2.33 & 42.2 & 68.3 \\
\hline & & & & & & & & & 41.2 & 51.0 \\
\hline & & & & & & & & & 46.8 & 66.5 \\
\hline & & & & & & 50 & 0.33 & 2.33 & 45.3 & 56.0 \\
\hline & & & & & & & & & 44.8 & 55.6 \\
\hline & & & & & & & & & 37.0 & 51.0 \\
\hline & & & & & 300 & 30 & 0.10 & 2.33 & 67.3 & 74.9 \\
\hline & & & & & & & & & 81.8 & 88.0 \\
\hline & & & & & & & & & 76.7 & 92.3 \\
\hline & & & & & & 60 & 0.20 & 2.33 & 71.2 & 73.6 \\
\hline & & & & & & & & & 65.5 & 76.8 \\
\hline & & & & & & & & & 74.2 & 85.3 \\
\hline & & & & & & 100 & 0.33 & 2.33 & 66.5 & 76.7 \\
\hline & & & & & & & & & 72.7 & 73.1 \\
\hline & & & & & & & & & 70.9 & 78.5 \\
\hline & & & & & 450 & 90 & 0.20 & 2.33 & 102.5 & 124.6 \\
\hline & & & & & & & & & 97.4 & 124.3 \\
\hline & & & & & & 150 & 0.33 & 2.33 & 96.5 & 101.4 \\
\hline & & & & & & & & & 93.1 & 105.4 \\
\hline & & & & & & & & & 97.0 & 97.7 \\
\hline
\end{tabular}


Table 1 (continued)

\begin{tabular}{|c|c|c|c|c|c|c|c|c|c|c|}
\hline Test series & Tree species & Strength class & $\frac{\text { Density }}{\left(\mathrm{kg} / \mathrm{m}^{3}\right)}$ & $\frac{B}{(\mathrm{~mm})}$ & $\begin{array}{l}H \\
(\mathrm{~mm})\end{array}$ & $\frac{D}{(\mathrm{~mm})}$ & $D / H$ & $M /(Q H)$ & $\frac{Q_{\operatorname{lni}}}{(\mathrm{kN})}$ & $\frac{Q_{\operatorname{Max}}}{(k N)}$ \\
\hline \multirow[t]{14}{*}{ OKAc [4] } & Scots pine & E105-F345 & $522 \pm 11$ & 105 & 150 & 30 & 0.20 & 2.33 & 49.9 & 61.2 \\
\hline & & & & & & & & & 52.3 & 56.6 \\
\hline & & & & & & 50 & 0.33 & 2.33 & 37.1 & 37.1 \\
\hline & & & & & & & & & 45.6 & 45.6 \\
\hline & & & & & 300 & 30 & 0.10 & 2.33 & 73.2 & 82.1 \\
\hline & & & & & & & & & 72.4 & 100.8 \\
\hline & & & & & & 60 & 0.20 & 2.33 & 68.0 & 91.2 \\
\hline & & & & & & & & & 73.5 & 88.0 \\
\hline & & & & & & 100 & 0.33 & 2.33 & 67.0 & 77.3 \\
\hline & & & & & & & & & 65.5 & 87.1 \\
\hline & & & & & 450 & 90 & 0.20 & 2.33 & 83.2 & 111.8 \\
\hline & & & & & & & & & 75.8 & 118.6 \\
\hline & & & & & & 150 & 0.33 & 2.33 & 80.9 & 103.0 \\
\hline & & & & & & & & & 81.4 & 98.8 \\
\hline \multirow[t]{6}{*}{ KAR [6] } & Douglas fir & E120-F330 & - & 120 & 300 & 100 & 0.33 & 0.67 & - & 54.9 \\
\hline & & & & & & & & 1.66 & - & 53.1 \\
\hline & & & & & & & & 2.67 & - & 52.1 \\
\hline & & & & & & & & 3.67 & - & 50.8 \\
\hline & & & & & & & & 4.16 & - & 39.7 \\
\hline & & & & & & & & 4.67 & - & 52.4 \\
\hline \multirow[t]{9}{*}{ HIJ [7] } & Scots pine & E120-F330 & - & 120 & 330 & 65 & 0.20 & 0.91 & 58.4 & 97.0 \\
\hline & & & & & & & & & 70.6 & 106.1 \\
\hline & & & & & & & & & 64.2 & 101.4 \\
\hline & & & & & & 130 & 0.39 & 0.91 & 53.2 & 93.4 \\
\hline & & & & & & & & & 45.7 & 82.9 \\
\hline & & & & & & & & & 63.6 & 101.5 \\
\hline & & & & & & 165 & 0.50 & 0.91 & 51.8 & 76.0 \\
\hline & & & & & & & & & 38.4 & 68.8 \\
\hline & & & & & & & & & 50.9 & 83.3 \\
\hline
\end{tabular}

$M$ is the bending moment at the center of the hole, $Q$ is the shear force at the center of the hole, $Q_{\operatorname{lni}}$ is the shear force at the center of the hole when the initial crack has propagated over the entire beam width, $Q_{\text {Max. }}$ is the shear force at the center of the hole at failure, E105-F300 and E120-F330 are GLT beams composed of heterogeneous glue, and represents the yield strength evaluated by the elastic-perfectly plastic model

of a hole fracture. Table 1 shows the experimental data for GLT beams in Japan [3, 4, 6, 7], and Table 2 shows the experimental data for GLT beams in countries other than Japan [8-13]. Table 2 uses the values summarized in detail by Danielsson [14].

\section{Material properties}

$E_{x}, F_{s}, F_{t 90}$, and $G_{I c}$ used in Eqs. (1) and (2) were obtained from the density of the wood in the area where a hole was provided. $E_{y}, G_{x y}$, and $v_{x y}$ were the same as those in the 2D-FEA, with $E_{y}=E_{x} / 25, G_{x y}=E_{x} / 15$, and $v_{x y}=0.4$. The density of the wood in the hole area was set to $522 \mathrm{~kg} /$ $\mathrm{m}^{3}$ for OKAc[4], $458 \mathrm{~kg} / \mathrm{m}^{3}$ for PEN [9], $489 \mathrm{~kg} / \mathrm{m}^{3}$ for HOF [12], and $471 \mathrm{~kg} / \mathrm{m}^{3}$ for AIC [13], as shown in Tables 1 and 2. OKAa [3], OKAb [3], KAR [6], and HIJ [7] are GLT beams composed of heterogeneous grades, and the density of the wood in the area where a hole is provided is not known. Therefore, the density was estimated from the grade of the inner layer lamina $(D / H=0.3$ at $H=150 \mathrm{~mm}$ for OKAa [3] and OKAb [3] is the middle layer lamina) in the area where the hole is provided. Figure 4 shows the relationship between the grade $L$ and 
Table 2 Experimental data of GLT beams with round holes from outside Japan [14]

\begin{tabular}{|c|c|c|c|c|c|c|c|c|c|c|}
\hline Test series & Tree species & Strength class & $\frac{\text { Density }}{\left(\mathrm{kg} / \mathrm{m}^{3}\right)}$ & $\begin{array}{l}B \\
(\mathrm{~mm})\end{array}$ & $\begin{array}{l}H \\
(\mathrm{~mm})\end{array}$ & $\begin{array}{l}D \\
(\mathrm{~mm})\end{array}$ & $D / H$ & $M /(Q H)$ & $\frac{Q_{\mathrm{Ini}}}{(\mathrm{kN})}$ & $\begin{array}{l}Q_{\text {Max }} \\
(k N)\end{array}$ \\
\hline \multirow[t]{2}{*}{ BEN [8] } & Spruce & $\llcorner 40$ & - & 90 & 500 & 250 & 0.50 & 1.20 & - & 37.5 \\
\hline & & & & & & & & & - & 39.2 \\
\hline \multirow[t]{4}{*}{ PEN [9] } & - & $\llcorner 40$ & $458 \pm 36$ & 90 & 500 & 255 & 0.51 & 1.20 & - & 33.8 \\
\hline & & & & & & 250 & 0.50 & 2.10 & - & 31.6 \\
\hline & & & & & & 150 & 0.30 & 1.20 & - & 51.3 \\
\hline & & & & 115 & 800 & 300 & 0.38 & 2.00 & - & 89.5 \\
\hline \multirow[t]{10}{*}{$\mathrm{JOH}[10]$} & Spruce & $\llcorner 40$ & - & 90 & 500 & 250 & 0.50 & 1.30 & 25.7 & 39.5 \\
\hline & & & & & & & & 1.30 & 33.4 & 33.4 \\
\hline & & & & & & & & 2.80 & 35.0 & 35.0 \\
\hline & & & & & & & & 2.80 & 31.3 & 39.9 \\
\hline & & & & & & & & 0.60 & 28.8 & 44.6 \\
\hline & & & & & & & & 0.60 & 38.8 & 38.8 \\
\hline & & & & 88 & 495 & 125 & 0.25 & 2.53 & 46.9 & - \\
\hline & & & & & & & & & 56.4 & - \\
\hline & & & & & & & & & 55.2 & - \\
\hline & & & & & & & & & 49.2 & - \\
\hline HAL [11] & Spruce & - & $350-550$ & 90 & 315 & 150 & 0.48 & 2.78 & 24.5 & - \\
\hline \multirow[t]{24}{*}{ HOF [12] } & Spruce & GL32h & 489 & 120 & 450 & 90 & 0.20 & 1.50 & 85.5 & 85.5 \\
\hline & & & & & & & & & 77.0 & 91.1 \\
\hline & & & & & & & & & 51.0 & 74.6 \\
\hline & & & & & & & & & 53.5 & 85.4 \\
\hline & & & & & & & & & 50.2 & 73.8 \\
\hline & & & & 120 & 450 & 135 & 0.30 & 1.50 & 52.5 & 59.3 \\
\hline & & & & & & & & & 75.0 & 75.0 \\
\hline & & & & & & & & & 69.4 & 77.2 \\
\hline & & & & & & & & & 62.6 & 62.6 \\
\hline & & & & & & & & & 66.7 & 66.7 \\
\hline & & & & & & & & & 66.5 & 66.5 \\
\hline & & & & 120 & 450 & 180 & 0.40 & 1.50 & 38.9 & 44.5 \\
\hline & & & & & & & & & 45.0 & 53.4 \\
\hline & & & & & & & & & 48.3 & 50.6 \\
\hline & & & & & & & & & 58.7 & 58.7 \\
\hline & & & & 120 & 900 & 180 & 0.20 & 1.50 & 88.0 & 119.2 \\
\hline & & & & & & & & & 86.1 & 110.0 \\
\hline & & & & & & & & & 90.0 & 114.2 \\
\hline & & & & & & & & & 117.0 & 144.8 \\
\hline & & & & & & & & & 150.7 & 152.5 \\
\hline & & & & 120 & 900 & 270 & 0.30 & 1.50 & 96.0 & 115.8 \\
\hline & & & & & & & & & 112.0 & 116.0 \\
\hline & & & & & & & & & 90.5 & 110.9 \\
\hline & & & & & & & & & 81.0 & 102.6 \\
\hline
\end{tabular}


Table 2 (continued)

\begin{tabular}{|c|c|c|c|c|c|c|c|c|c|c|}
\hline Test series & Tree species & Strength class & $\frac{\text { Density }}{\left(\mathrm{kg} / \mathrm{m}^{3}\right)}$ & $\frac{B}{(\mathrm{~mm})}$ & $\begin{array}{l}H \\
(\mathrm{~mm})\end{array}$ & $\frac{D}{(\mathrm{~mm})}$ & $D / H$ & $M /(Q H)$ & $\frac{Q_{\mathrm{Ini}}}{(\mathrm{kN})}$ & $\begin{array}{l}Q_{\max } \\
(k N)\end{array}$ \\
\hline & & & & & & & & & 90.9 & 104.9 \\
\hline & & & & & & & & & 108.2 & 112.1 \\
\hline & & & & 120 & 900 & 360 & 0.40 & 1.50 & - & 81.9 \\
\hline & & & & & & & & & 67.5 & 72.4 \\
\hline & & & & & & & & & 84.0 & 117.3 \\
\hline & & & & & & & & & 60.0 & 85.4 \\
\hline & & & & & & & & & 69.0 & 79.3 \\
\hline & & & & & & & & & 65.3 & 88.8 \\
\hline & & & & 120 & 450 & 135 & 0.30 & 5.00 & 58.5 & 58.5 \\
\hline & & & & & & & & & 70.0 & 70.0 \\
\hline & & & & & & & & & 52.4 & 68.1 \\
\hline & & & & & & & & & 54.8 & 54.8 \\
\hline & & & & & & & & & 54.1 & 65.6 \\
\hline & & & & 120 & 900 & 270 & 0.30 & 5.00 & 48.0 & 95.6 \\
\hline & & & & & & & & & 50.9 & 74.1 \\
\hline & & & & & & & & & 50.0 & 93.8 \\
\hline & & & & & & & & & 69.2 & 100.1 \\
\hline & & & & & & & & & 57.5 & 57.5 \\
\hline \multirow[t]{15}{*}{$\operatorname{AIC}[13]$} & Spruce & GL $32 \mathrm{~h}$ & $471 \pm 38$ & 120 & 450 & 180 & 0.40 & 5.00 & 50.0 & 61.0 \\
\hline & & & & & & & & & 63.5 & 63.5 \\
\hline & & & & & & & & & 43.8 & 44.0 \\
\hline & & & & & & & & & 46.7 & 48.0 \\
\hline & & & & & & & & & 46.7 & 57.5 \\
\hline & & & & & & & & & 42.0 & 48.0 \\
\hline & & & & 120 & 900 & 180 & 0.20 & 5.00 & 107.1 & 107.1 \\
\hline & & & & & & & & & 101.4 & 101.4 \\
\hline & & & & & & & & & 126.4 & 126.4 \\
\hline & & & & & & & & & 90.6 & - \\
\hline & & & & 120 & 900 & 360 & 0.40 & 5.00 & 62.6 & 82.7 \\
\hline & & & & & & & & & 77.2 & 77.2 \\
\hline & & & & & & & & & 68.5 & 82.7 \\
\hline & & & & & & & & & 62.5 & - \\
\hline & & & & & & & & & 37.0 & 77.0 \\
\hline
\end{tabular}

$M$ is the bending moment at the center of the hole, $Q$ is the shear force at the center of the hole, $Q_{\ln \text { i. }}$ is the shear force at the center of the hole when the initial crack has propagated over the entire beam width, $Q_{\text {Max. }}$ is the shear force at the center of the hole at failure, and $\mathbf{\square}$ represents the average value of 5 test specimens 


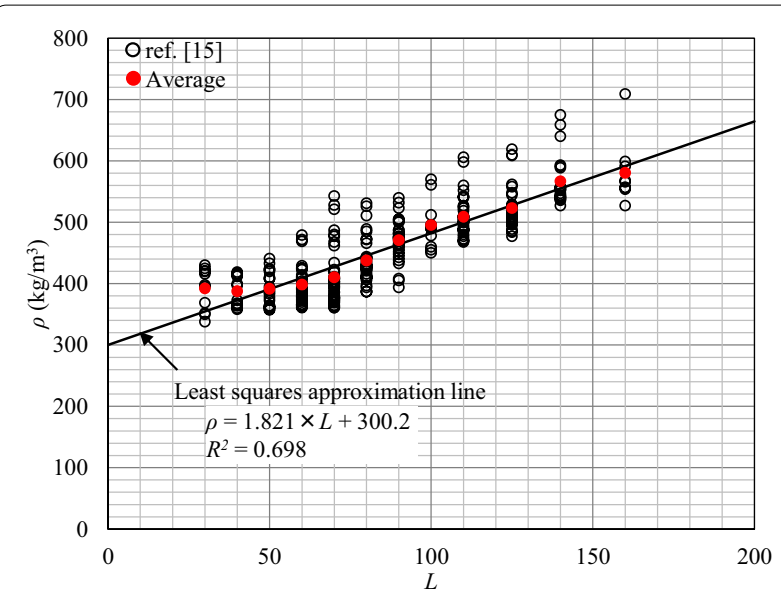

Fig. 4 Relationship between lamina grade $L$ and density $\rho$

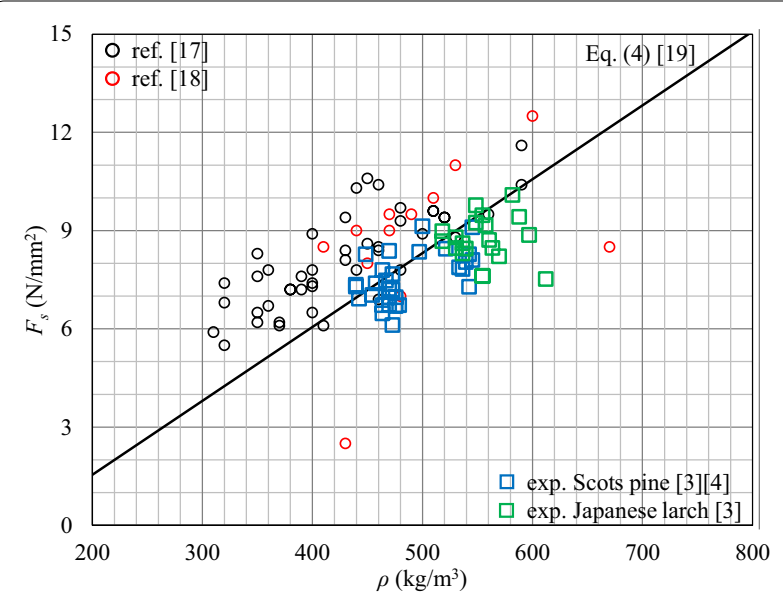

Fig. 6 Relationship between shear strength $F_{s}$ and density $\rho$

density $\rho$ of the specimens extracted from the existing experimental lamina data [15]. The density of the lamina was taken as obtained from the least-squares approximation line in Fig. 4, which is $446 \mathrm{~kg} / \mathrm{m}^{3}$ for the inner lamina of OKAa [3] and OKAb [3] with L80, $482 \mathrm{~kg} / \mathrm{m}^{3}$ for the middle layer lamina of OKAa [3] and OKAb [3] with L100, and $464 \mathrm{~kg} / \mathrm{m}^{3}$ for the inner lamina of KAR [6] and HIJ [7] with L90. BEN [8] and JOH [10] are assumed to be equivalent to PEN [9] of the same grade, so $458 \mathrm{~kg} / \mathrm{m}^{3}$ is used. HAL [11] ranges from 350 to $550 \mathrm{~kg} / \mathrm{m}^{3}$, so an intermediate value of $450 \mathrm{~kg} / \mathrm{m}^{3}$ is used.

$E_{x}$ was obtained from the density $\rho$ of wood using Eq. (3) [16]:

$$
E_{x}\left(\mathrm{~N} / \mathrm{mm}^{2}\right)=23.536 \times \rho\left(\mathrm{kg} / \mathrm{m}^{3}\right) .
$$

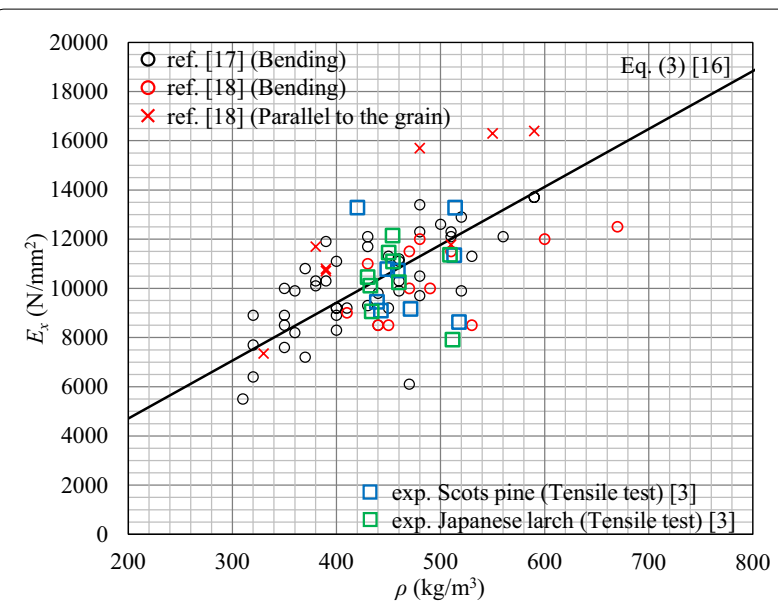

Fig. 5 Relationship between the modulus of elasticity, parallel to grain $E_{x}$ and density $\rho$

Figure 5 shows a comparison of the results of Eq. (3) with existing intensity data $[17,18]$ and previous experimental data [3]. Since the lamina grade shows the lower limit, using the least-squares approximation line in Fig. 4 and Eq. 3 results in a value higher than the lamina grade.

$F_{s}$ was obtained from the density $\rho$ of wood using Eq. (4) [19]:

$$
F_{s}\left(\mathrm{~N} / \mathrm{mm}^{2}\right)=0.02256 \times \rho\left(\mathrm{kg} / \mathrm{m}^{3}\right)-2.97 .
$$

Figure 6 shows a comparison of Eq. (4) with existing intensity data $[17,18]$ and previous experimental data $[3$, 4].

$F_{t 90}$ was obtained by multiplying $F_{s}$ by a constant. According to the "Standard for Structural Design of Timber Structures" (Japan) [20], $F_{s}$ was multiplied by $1 / 3$ to obtain $F_{t 90}$, so the constant was set to $1 / 3$. However, $F_{t 90}$ of Japanese larch is low [3], and a load of splitting fracture perpendicular to the grain against the density has also been confirmed to be lower in Japanese larch than in spruce, Japanese cedar, and Douglas fir [21]. Therefore, the constant was determined separately for Japanese larch. Figure 7 shows a comparison of the calculated values of $F_{t 90}$ with existing intensity data [17] and experimental data from the authors' previous studies $[3,4,22]$. Figure 8 shows a schematic diagram of the test method used to determine $F_{t 90}$ in the authors' previous studies $[3,4,22]$. In the studies of beams with round holes [3, 4], a specimen height of $h=150 \mathrm{~mm}$ was used, but in the study of the tension perpendicular to the grain strength of the GLT beams of Scots pine [22], a specimen height of $h=100 \mathrm{~mm}$ was found to be optimal. Although the optimum value of specimen height $h$ 


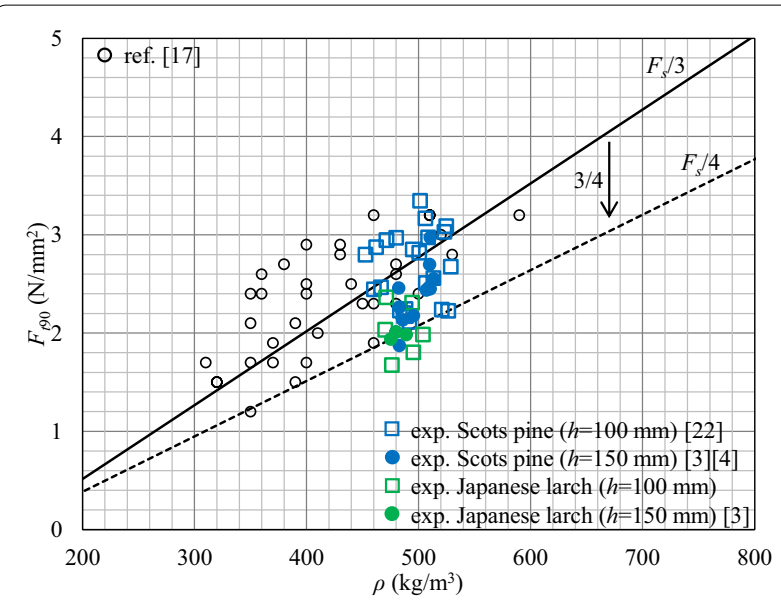

Fig. 7 Relationship between the tensile strength perpendicular to the grain $F_{t 90}$ and density $\rho$

for Japanese larch is not known, Fig. 7 shows the experimental values for $h=150 \mathrm{~mm} \mathrm{[3]} \mathrm{and} \mathrm{new} \mathrm{experimental}$ values for $h=100 \mathrm{~mm}$. Since the experimental values of $h=100 \mathrm{~mm}$ and $h=150 \mathrm{~mm}$ for larch are almost the same, it was assumed that $h=100 \mathrm{~mm}$ and $h=150 \mathrm{~mm}$ are the optimum values for $F_{t 90}$. Then, based on the results in Fig. 7 , the constant multiplied by $F_{s}$ for Japanese larch was set to $1 / 4$.

Equation (5) was used to obtain $G_{\mathrm{I} c}$ from the density $\rho$ of wood [23]:

$$
G_{\mathrm{I} c}\left(\mathrm{~N} \cdot \mathrm{m} / \mathrm{m}^{2}\right)=1.07 \times \rho\left(\mathrm{kg} / \mathrm{m}^{3}\right)-162 .
$$

Figure 9 shows a comparison of the results from Eq. (5) with the experimental data from the authors' previous studies $[3,4,24]$. Since Japanese larch has low $G_{\mathrm{I} c}$ and $F_{t 90}$ values, we decided to use the value obtained by multiplying Eq. (5) by $3 / 4$ as the same reduction for $F_{t 90}$.

\section{Results and discussion \\ FE results \\ (1) Analysis around the hole}

The tensile stresses perpendicular to the grain $\sigma_{Q}$ and $\sigma_{M}$ and the shear stresses $\tau_{Q}$ and $\tau_{M}$ acting around the hole obtained from the analysis in Fig. 3 and Additional file 1: Fig. S1 are shown in Fig. 10. The stresses when only shear force $Q$ acts on the center of the hole are $\sigma_{Q}$ and $\tau_{Q}$, and the stress levels when only bending moment $M$ acts on the hole are $\sigma_{M}$ and $\tau_{M}$. The vertical axis represents the stress/ maximum stress, with the maximum value normalized to 1.0. The horizontal axis represents $y / D$. The stresses acting on the hole are symmetric or inversely symmetric with respect to the center of the hole [4], so only a quarter of the hole is shown in Fig. 10. From Fig. 10, it was found that the

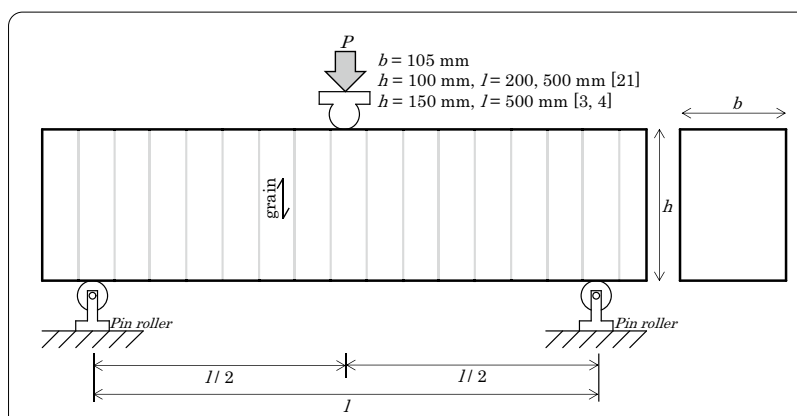

Fig. 8 Bending test method of tensile strength perpendicular to the grain

stress distribution is different from $D / H$ of 0.6 or more but almost the same when $D / H$ is 0.5 or less. This indicates that there is a possibility to approximate the stress distribution with a simple equation when $D / H$ is 0.5 or less.

Therefore, the coefficients $\alpha_{Q}$ and $\alpha_{M}$ for finding $Q=\alpha_{Q} \tau_{1} B H$ and $M=\alpha_{M} \tau_{1} B H^{2}$ acting when the maximum values of $\sigma_{Q}$ and $\sigma_{M}$ are almost $1.0 \mathrm{~N} / \mathrm{mm}^{2}$ were derived from $\sigma_{Q, \max }$ and $\sigma_{M, \max }$ in Fig. 10. $\alpha_{Q}$ is shown in Eq. (6), and $\alpha_{Q}$ is shown in Eq. (7). Equations (6) and (7) were obtained by trial and error to make them as simple as possible:

$$
\begin{aligned}
\alpha_{Q} & =\frac{1}{3 \cdot(D / H)^{2}+2}(D / H \leq 0.5) \\
\alpha_{M} & =\frac{1.5}{D / H}(D / H \leq 0.5)
\end{aligned}
$$

$\sigma_{Q}$ and $\tau_{Q}$ when $Q=\alpha_{Q} \tau_{1} B H$ and $\sigma_{M}$ and $\tau_{M}$ when $M=\alpha_{M} \tau_{1} B H^{2}$ are shown in Fig. 11. $\sigma_{Q, \max }$ is at $y \approx 0.38 D$ and $\sigma_{M, \max }$ is at $y \approx 0.25 D$. Additional file 1 : Table S1 shows the coefficients obtained by regressing the stress distribution of $\sigma_{Q}, \sigma_{M}, \tau_{Q}$ and $\tau_{M}$ in the range of $0.2 D \leq y \leq 0.4 D$ in Fig. 11 with the 5 th-order polynomial in Eq. (8):

$$
\sigma_{Q}, \sigma_{M}, \tau_{Q}, \tau_{M}=\sum_{k=0}^{5} a_{k} \cdot\left(\frac{y}{D}\right)^{k} .
$$

The effect of $\sigma$ on the splitting fracture of the hole is very large, while the effect of $\tau$ is very small (since $k_{\tau}=1.015$ 1.075 in Eq. (17), the effect of shear stress is approximately $1.5-7.5 \%)$. Therefore, it is assumed that the splitting fracture of the hole is in the range of $0.25 \leq y / D \leq 0.40$ $\left(30^{\circ} \leq \theta \leq 53^{\circ}\right.$ in Fig. 1) to derive the bearing capacity formula. 


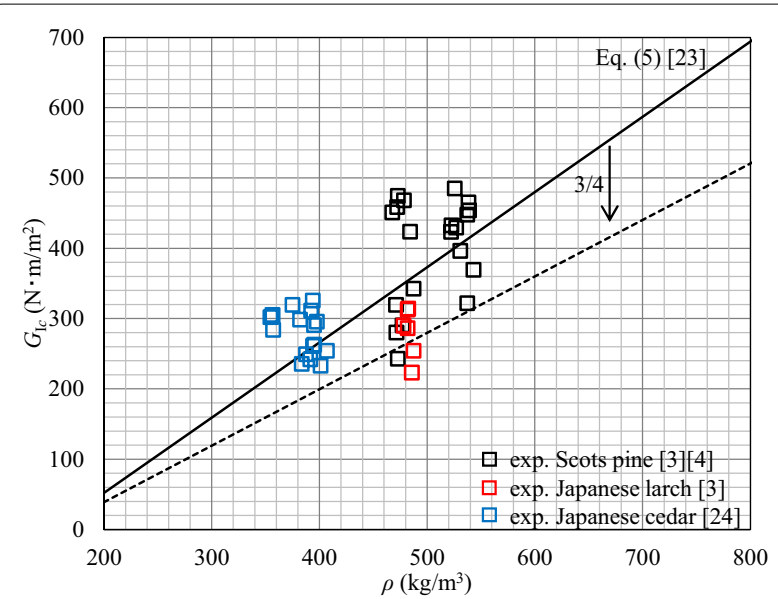

Fig. 9 Relationship between mode I fracture energy $G_{\mid c}$ and density $\rho$

\section{(2) Analysis of the stress distribution in the direction parallel to the grain}

A part of the stress distributions of $\sigma_{Q}, \sigma_{M}, \tau_{Q}$ and $\tau_{M}$ in the direction parallel to the grain ( $x$-direction) obtained from the analysis of Fig. 3 and Additional file 1: Fig. S2 is shown in Additional file 1: Fig. S3. The abscissa is $x / D$, and the stress distribution originates around the hole. The stress when only shear force $Q$ acts on the center of the hole is $\sigma_{Q}$ and $\tau_{Q}$, and the stress level when only bending moment $M$ acts on the hole is $\sigma_{M}$ and $\tau_{M}$. In the case of $D / H=0.5$, there was a slight deviation, but the stress distributions were almost the same. Additionally, although not shown in the figure, the stress distributions were almost the same except when $y / D=0.25$ and 0.40 . This indicates that it is possible to approximate the stress distribution with a simple equation. Additional file 1: Tables S2 and S3 show the coefficients obtained by regressing the stress distributions of $\sigma_{Q}, \sigma_{M}, \tau_{Q}$ and $\tau_{M}$ in the direction parallel to the grain ( $x$-direction) in the range of $0.0 \leq x / D \leq 0.5$ obtained from the analysis in Fig. 3 and Additional file 1: Fig. S2 with the 5th-order polynomial in Eq. (9):

$$
\sigma_{Q}, \sigma_{M}, \tau_{Q}, \tau_{M}=\sum_{k=0}^{5} a_{k} \cdot\left(\frac{x}{D}\right)^{k} .
$$

Figure 12 (A case of $D / H=0.3$ ) shows a part of the result of the calculation obtained by Eq. (9) and Additional file 1: Tables S2 and S3. The average stress in the length $x$ in the direction parallel to the grain can then be obtained by Eq. (10) using the coefficients in Additional file 1: Tables S2 and S3:

$$
\bar{\sigma}_{Q}, \bar{\sigma}_{M}, \bar{\tau}_{Q}, \bar{\tau}_{M}=\sum_{k=0}^{5} \frac{a_{k}}{k+1} \cdot\left(\frac{x}{D}\right)^{k} .
$$

Formulation of the maximum stress acting around the hole $\bar{\sigma}_{Q}, \bar{\tau}_{Q}, \bar{\sigma}_{M}$ and $\bar{\tau}_{M}$ can be obtained from Eq. (10) by finding the constant length $x$ in the direction parallel to the grain in Eq. (2) and from $Q$ and $M$ acting on the hole. Then, it is possible to determine the bearing capacity of the hole at the time of splitting fracture using Eq. (1) via $\bar{\sigma}=\bar{\sigma}_{Q}+\bar{\sigma}_{M}$ and $\bar{\tau}=\bar{\tau}_{Q}+\bar{\tau}_{M}$. However, the left side of Eq. (1) is very time consuming to compute because the maximum value needs to be obtained. Therefore, it was decided to formulate the maximum value of the left side of Eq. (1) and derive a relatively simple equation for determining the bearing capacity at the time of splitting fracture of a hole. The left side of Eq. (1) is difficult to formulate because it is a compound stress equation and therefore cannot be obtained from the maximum values of $\bar{\sigma}$ and $\bar{\tau}$. Therefore, since the effect of $\tau$ on the splitting fracture of a hole is very small (since $k_{\tau}=1.015$ to 1.075 in Eq. (17), the effect of shear stress is approximately $1.5 \%$ to $7.5 \%$ ), and we decided to change the left side of Eq. (1) to Eq. (11) and formulate it by expressing the effect of $\tau$ in terms of the incremental coefficient of stress:

$$
\frac{k_{\tau} \cdot \bar{\sigma}_{\max }}{F_{t 90}}=\max \left\{\sqrt{\left(\frac{\bar{\sigma}}{F_{t 90}}\right)^{2}+\left(\frac{\bar{\tau}}{F_{s}}\right)^{2}}\right\} .
$$

\section{(1) Maximum value of $\sigma$ around the hole}

Since the maximum value of $\sigma_{Q}$ when $Q=\alpha_{Q} \tau_{1} B H$ $\left(\tau_{1}=1 \mathrm{~N} / \mathrm{mm}^{2}\right)$ is $1 \mathrm{~N} / \mathrm{mm}^{2}$ and the maximum value of $\sigma_{M}$ when $M=\alpha_{M} \tau_{1} B H^{2}\left(\tau_{1}=1 \mathrm{~N} / \mathrm{mm}^{2}\right)$ is $1 \mathrm{~N} / \mathrm{mm}^{2}$, the maximum values of $\sigma_{Q}$ and $\sigma_{M}$ can be obtained using Eqs. (12) and (13):

$$
\begin{aligned}
\sigma_{Q, \max } & =\frac{3 \cdot(D / H)^{2}+2}{B \cdot H} \cdot Q, \\
\sigma_{M, \max } & =\frac{D / H}{1.5 \cdot B \cdot H^{2}} \cdot M .
\end{aligned}
$$

$\sigma=\sigma_{Q}+\sigma_{M}$, but $\sigma_{\max }=\sigma_{Q, \max }+\sigma_{M, \max }$ is not true. Therefore, the FE results in Eq. (9) and Additional file 1: Table $S 2$ can be used to obtain the relationship between $M /$ $(Q H)$ and $\sigma_{\max }$ by determining the relationship between $M /$ $(Q H)$ and $\sigma$ for $y=0.25 D$ to $0.40 D$, as shown in Additional file 1: Fig. S4 (a case of $D / H=0.3$ ). Then, an approximation 


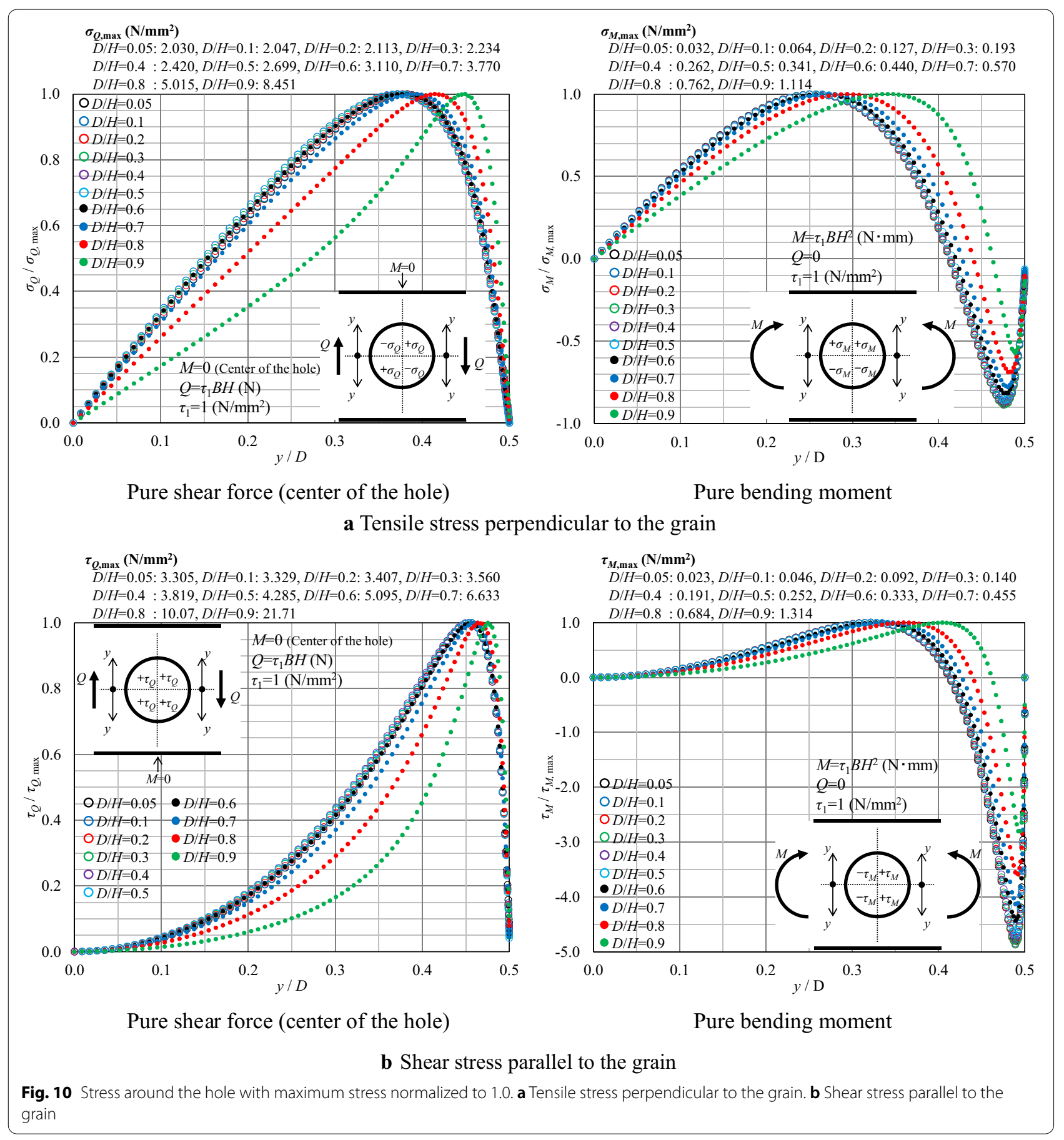




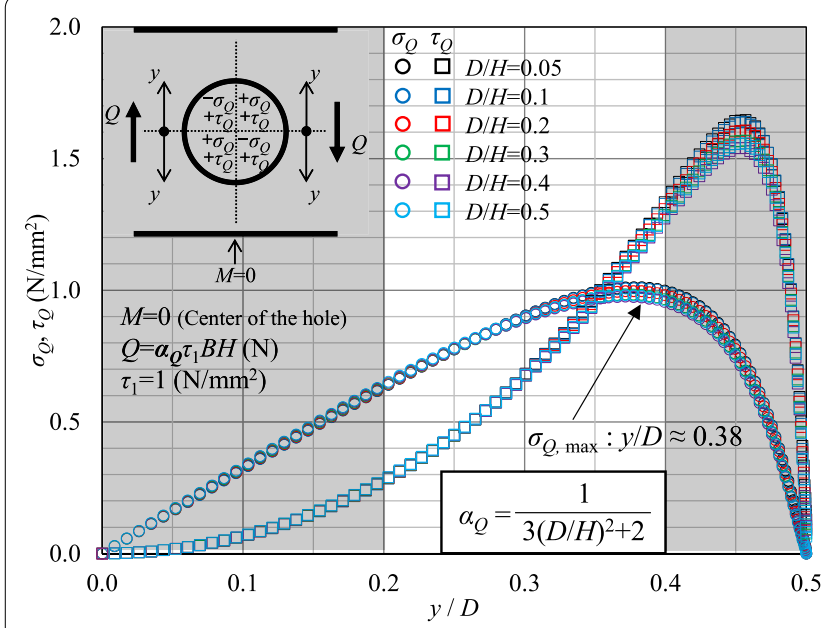

Pure shear force (center of the hole)

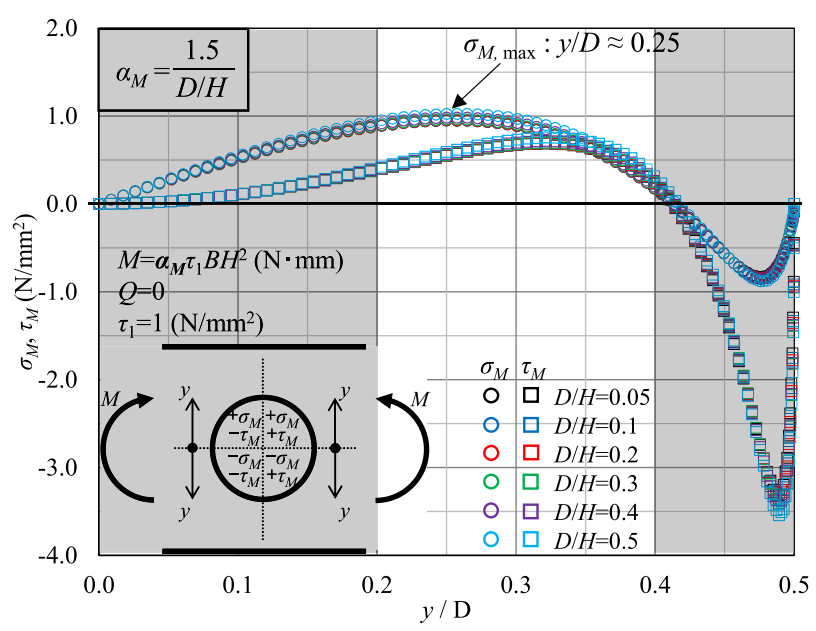

Pure bending moment

Fig. 11 Stress around the hole normalized by $a_{Q}$ or $a_{M}$

formula for $\sigma_{\max }$ (Eq. (14)) using Eqs. $(12,13)$ was created by trial and error to make the formula as simple as possible:

$$
\begin{aligned}
& \sigma_{\max }=\sigma_{Q, \max }+\sigma_{M, \max } \cdot k_{M / Q}, \\
& k_{M / Q}=\frac{0.7}{\frac{Q \cdot H}{M} \cdot \frac{H}{D}+1}+0.3 .
\end{aligned}
$$

A comparison between the FE results for $\sigma_{\max }$ and the calculation results of Eq. (14) is shown in Fig. 13. It was confirmed that the results can be estimated with good accuracy in the range of $M /(Q H)=1-100$.

\section{(2) Maximum value of $\bar{\sigma}$ around the hole}

Using the FE results in Eq. (10) and Additional file 1: Table S2, we obtained the relationship between $x / D$ and $\bar{\sigma}$ for $y=0.25 D$ to $0.40 D$, as shown in Additional file 1: Fig. S5 (a case of $D / H=0.3, M /(Q H)=0.1,5,10,100$ ). We obtained the relationship between $x / D$ and $\bar{\sigma}_{\max }$ for each $M /(Q H)$. Then, an approximation formula for $\bar{\sigma}_{\max }$ (Eq. (15)) using Eqs. (12-14) was created by trial and error to make the formula as simple as possible:

$$
\begin{aligned}
\bar{\sigma}_{\max } & =\sigma_{Q, \max } \cdot k_{Q, \mathrm{~ms}}+\sigma_{M, \max } \cdot k_{M / Q} \cdot k_{M, \mathrm{~ms}}, \\
k_{Q, \mathrm{~ms}} & =\frac{1}{1+1.8 \cdot x / D} \\
k_{M, \mathrm{~ms}} & =1.6 \cdot k_{Q, \mathrm{~ms}}-0.6 .
\end{aligned}
$$

A comparison between the FE results for $\bar{\sigma}_{\max }$ and the calculation results of Eq. (15) is shown in Fig. 14. (A case of $D / H=0.3$. All results are shown in Additional file 1:
Fig. S6.) It was confirmed that the results can be estimated with good accuracy in the range of $M /(Q H)=0.1-$ 100 , although there is a slight shift when $x / D$ is large.

\section{(3) Maximum value of $\bar{\sigma}$ incorporating the effect of shear stress around the hole}

The effect of the shear stress is determined by Eq. (16), which is the reformulation of Eq. (11) obtained using the FE results in Eq. (10) and Additional file 1: Tables S2 and S3:

$$
k_{\tau} \cdot \bar{\sigma}_{\max }=\max \left\{\sqrt{\left(\bar{\sigma}_{Q}+\bar{\sigma}_{M}\right)^{2}+\left(\frac{\bar{\tau}_{Q}+\bar{\tau}_{M}}{F_{s} / F_{t 90}}\right)^{2}}\right\} .
$$

The FE results in Eq. (10) and Additional file 1: Tables S2 and S3 were used to obtain the relationship between $x / D$ and $k_{\tau} \cdot \bar{\sigma}$ for $y=0.25 D$ to $0.40 D$, as shown in Additional file 1: Fig. S7 (a case of $D / H=0.3, F_{s} / F_{t 90}=3.0$, and $M /(Q H)=0.1,5,10,100)$. We obtained the relationship between $x / D$ and $k_{\tau} \cdot \bar{\sigma}_{\max }$ for each $M /(Q H)$. Then, an approximation formula for $k_{\tau}$ (Eq. (17)) was created by trial and error to make the formula as simple as possible. However, since we judged from Fig. 9 that $F_{s} / F_{t 90}=3$ to 4 , we only obtained $k_{\tau}$ for the cases of $F_{s} / F_{t 90}=3.0,3.5$, and 4.0:

$$
k_{\tau}=A+B \cdot e^{-0.1 \cdot \frac{M}{Q H}},
$$

where $A=1.025$ and $B=0.05$ for $F_{s} / F_{t 90}=3.0 . A=1.02$ and $B=0.035$ for $F_{s} / F_{t 90}=3.5 . A=1.015$ and $B=0.025$ for $F_{s} / F_{t 90}=4.0$. 


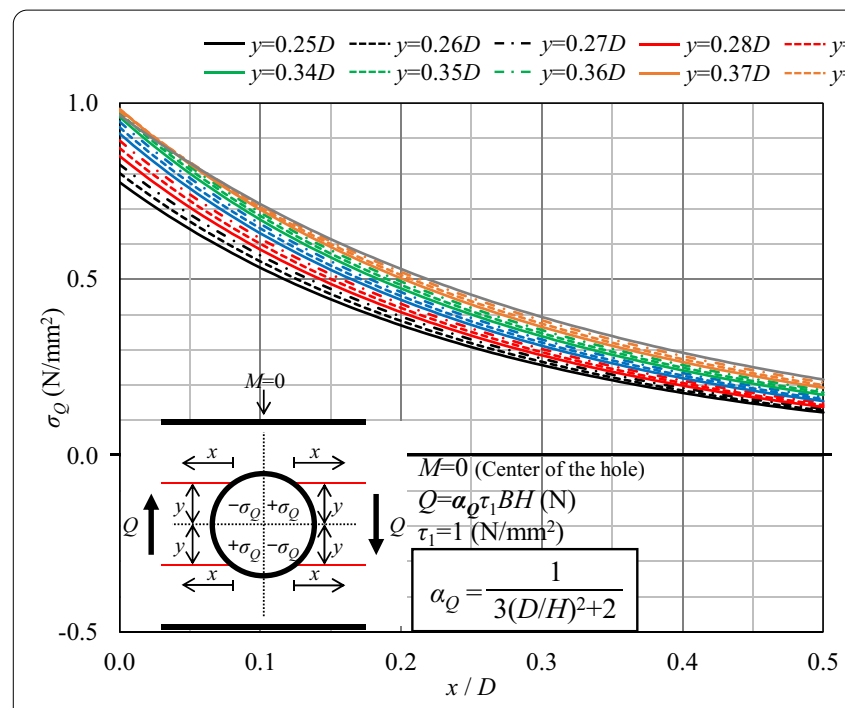

Pure shear force (center of the hole)

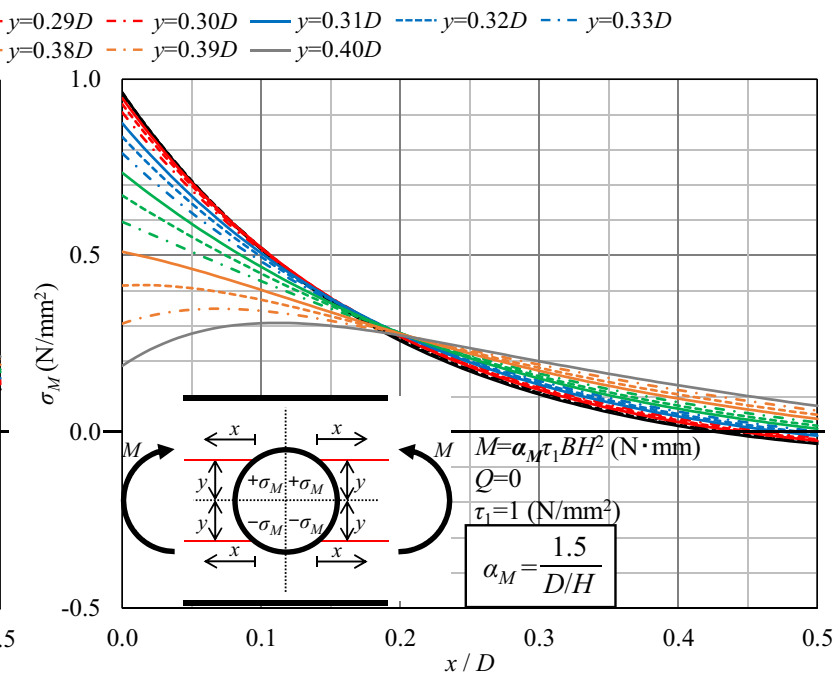

Pure bending moment

a Tensile stress perpendicular to the grain

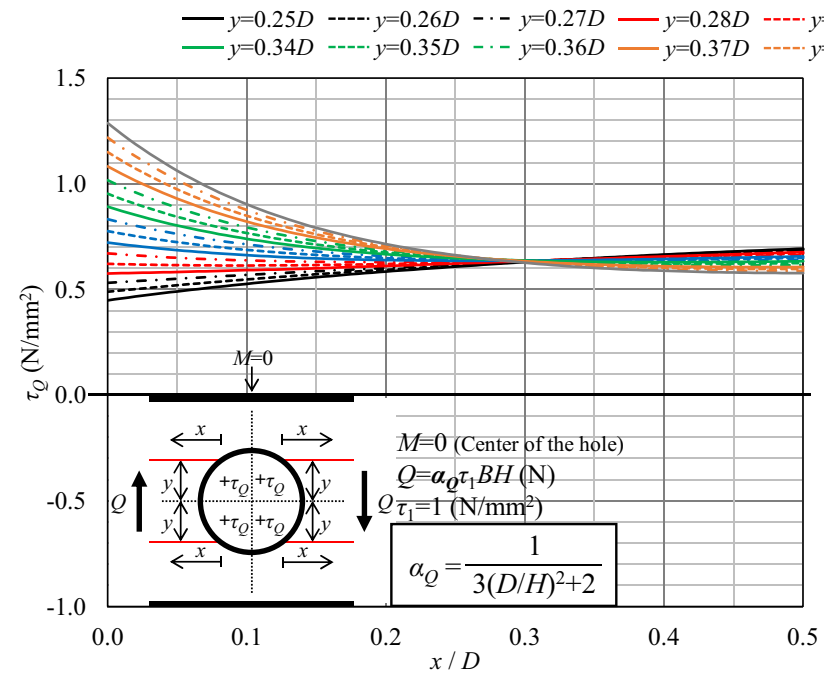

Pure shear force (center of hole)

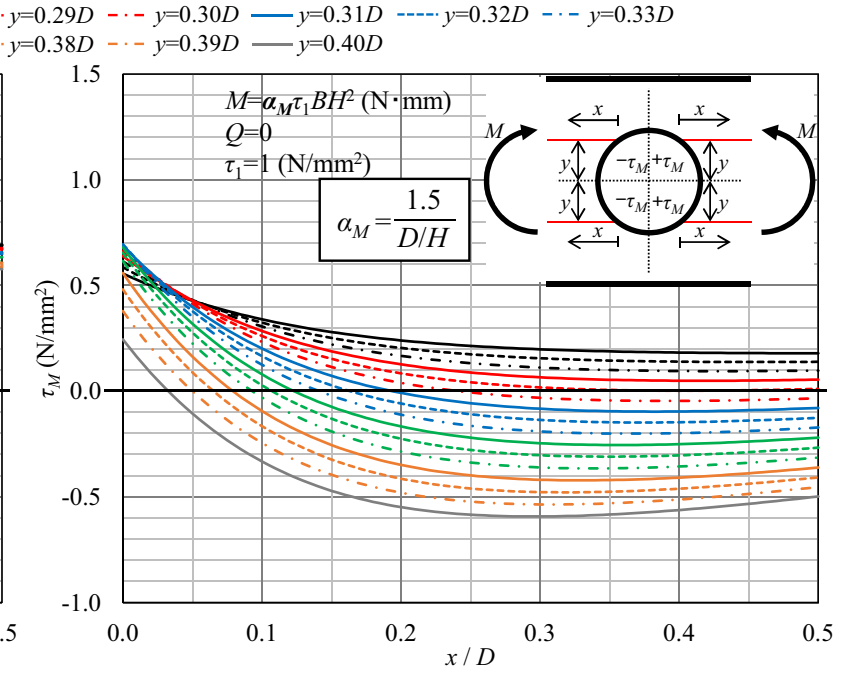

Pure bending moment

b Shear stress parallel to the grain

Fig. 12 Results of the calculations using Eq. (9) and Additional file 1:Tables S2 and S3 for the stress distribution. D/H=0.3. a Tensile stress perpendicular to the grain; $\mathbf{b}$ shear stress parallel to the grain

Comparisons between the $\mathrm{FE}$ results for $k_{\tau} \bar{\sigma}_{\max }$ and the calculation results of Eqs. (12-15) and (17) are shown in Fig. 15. (A case of $D / H=0.3, F_{s} / F_{t 90}=3.0$. All results are shown in Additional file 1: Figs. S8-10.) It was confirmed that the results can be estimated with good accuracy in the range of $M /(Q H)=0.1-100$, although there is a slight shift when $x / D$ is large. $k_{\tau}=1.025$ to 1.075 for $F_{s} / F_{t 90}=3.0, k_{\tau}=1.02$ to 1.055 for $F_{s} / F_{t 90}=3.5$, and $k_{\tau}=1.015$ to 1.04 for $F_{s} / F_{t 90}=4.0$, thereby indicating that the effect of shear stress is small.

\section{(4) Maximum value of $\bar{\sigma}$ around the hole in GLT beams composed of heterogeneous grades}

When a hole is made in the inner lamina of a GLT beam composed of heterogeneous grades, the stress acting on the hole is smaller than that of a GLT beam composed of homogeneous grades [4]. By multiplying the stress acting on the hole in the GLT beam composed of homogeneous grades by the reduction coefficient in Table 3 [4], as shown in Fig. 16, the stress acting on the hole in the inner lamina of the GLT beam composed of heterogeneous grades in 


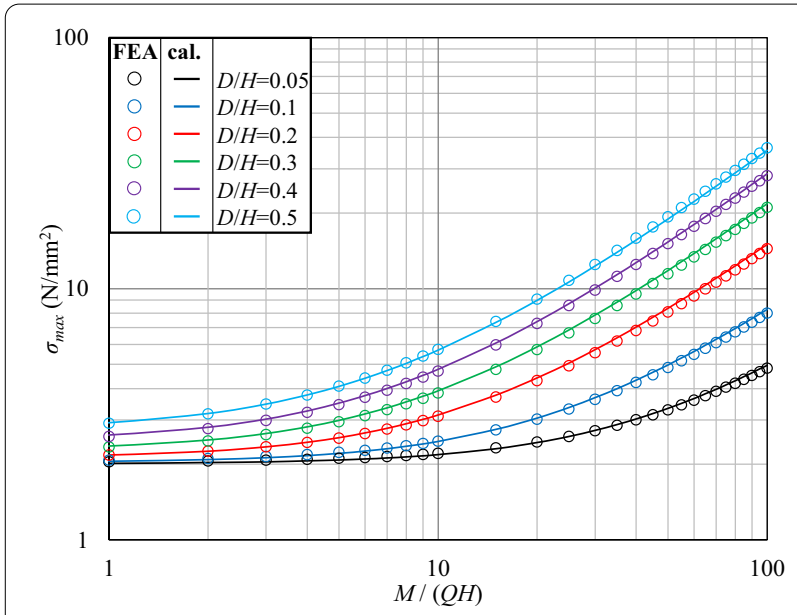

Fig. 13 Comparison of the FEA results (Fig. 16) and calculated values (Eq. (14)) for $\sigma_{\max } \sigma_{\max }$ is the stress when $Q=\tau_{1} B H$ and $M=\tau_{1} B H^{2}$ are acting

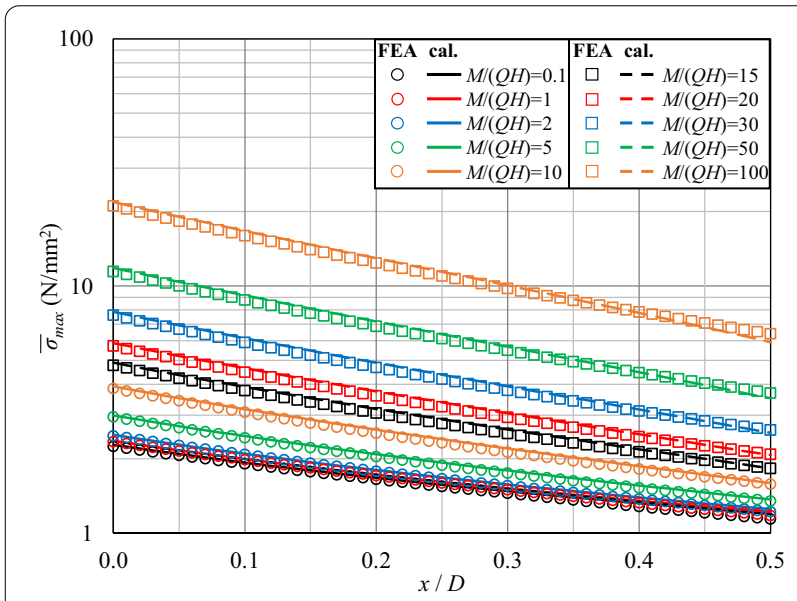

Fig. 14 Comparison of the FEA results and calculated values (Eq. (15)) for $\bar{\sigma}_{\text {max }}$. $D / H=0.3 . \bar{\sigma}_{\text {max }}$ is the stress when $Q=\tau_{1} B H$ is acting

JAS [2] can be obtained. The reduction coefficient from Table 3 to Eqs. (1-2), (12-15), and (17) can be added, and the design equation for splitting fracture of a hole in a GLT beam with a round hole is given in Eq. (18):

$$
\begin{aligned}
& \frac{k_{\tau} \cdot \bar{\sigma}_{\max }}{F_{t 90} \cdot k_{\mathrm{vol}}} \leq 1 \\
& k_{\mathrm{vol}}=\left(\frac{30}{\max (0.2 D, 30)}\right)^{0.14},
\end{aligned}
$$

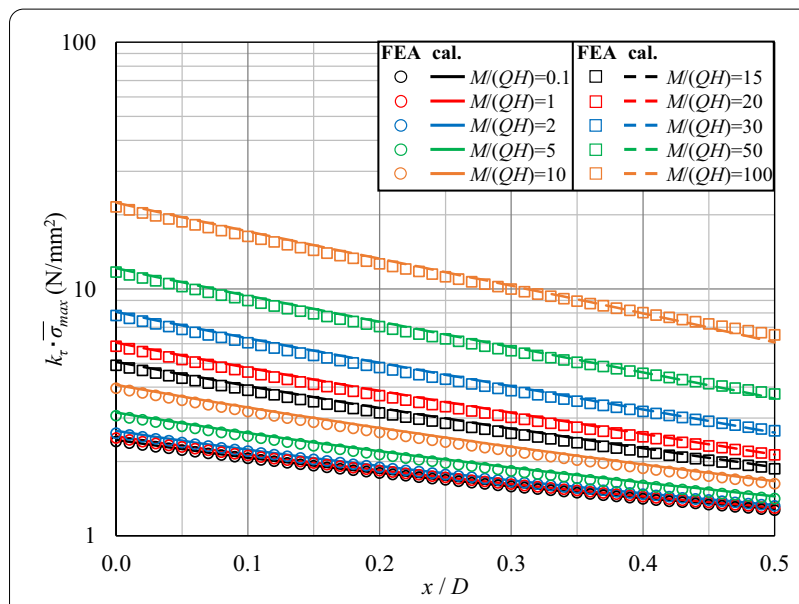

Fig. 15 Comparison of the FEA results and calculated values (Eq. (15, 17)) for $k_{\tau} \bar{\sigma}_{\max } . D / H=0.3, F_{s} / F_{t 90}=3.0 . k_{\tau} \bar{\sigma}_{\max }$ is the stress when $Q=\tau_{1} B H$ is acting

Table 3 Stress reduction factor for GLT beams composed of heterogeneous grade [4]

\begin{tabular}{lll}
\hline Strength grade & $\boldsymbol{k}_{\boldsymbol{M} \text {,comp }}$ & $\boldsymbol{k}_{\mathbf{Q}, \text { comp }}$ \\
\hline E170-F495 & 0.72 & 0.95 \\
E150-F435 & 0.71 & 0.95 \\
E135-F375 & 0.73 & 0.95 \\
E120-F330 & 0.74 & 0.95 \\
E105-F300 & 0.74 & 0.95 \\
E95-F270 & 0.72 & 0.95 \\
E85-F255 & 0.69 & 0.94 \\
E75-F240 & 0.65 & 0.94 \\
E65-F225 & 0.60 & 0.93 \\
E55-F200 & 0.53 & 0.91 \\
\hline
\end{tabular}

$$
\begin{aligned}
& k_{\tau}=A+B \cdot e^{-0.1 \cdot \frac{M}{Q H}}, \\
& \bar{\sigma}_{\max }= \sigma_{Q, \max } \cdot k_{Q, \mathrm{~ms}} \cdot k_{Q, \mathrm{comp}} \\
&+\sigma_{M, \max } \cdot k_{M / Q} \cdot k_{M, \mathrm{~ms}} \cdot k_{M, \mathrm{comp}}, \\
& \sigma_{Q, \max }= \frac{3 \cdot(D / H)^{2}+2}{B \cdot H} \cdot \mathrm{Q}, \\
& \sigma_{M, \max }=\frac{D / H}{1.5 \cdot B \cdot H^{2}} \cdot M, \\
& k_{M / Q}=\frac{0.7}{\frac{Q \cdot H}{M} \cdot \frac{H}{D}+1}+0.3,
\end{aligned}
$$




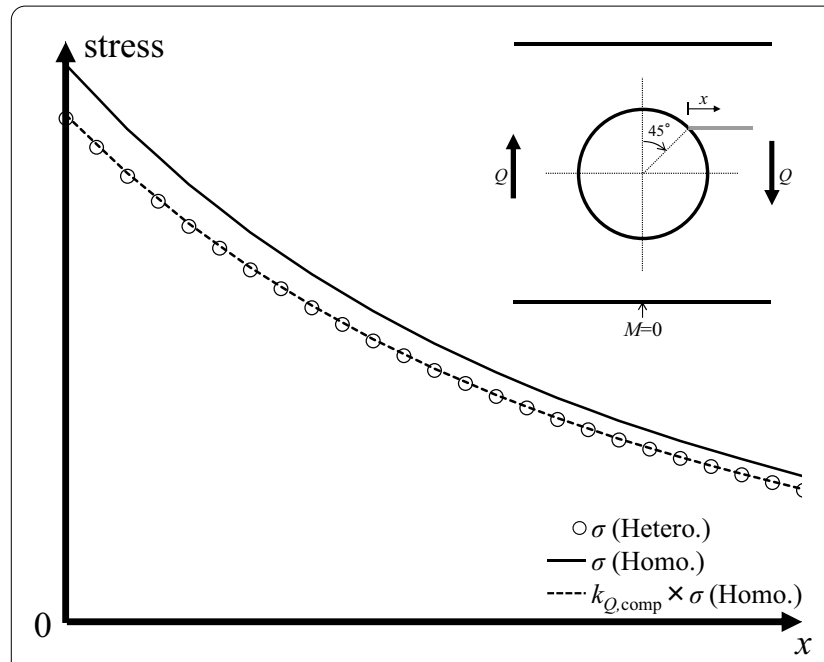

Pure shear force (center of the hole)

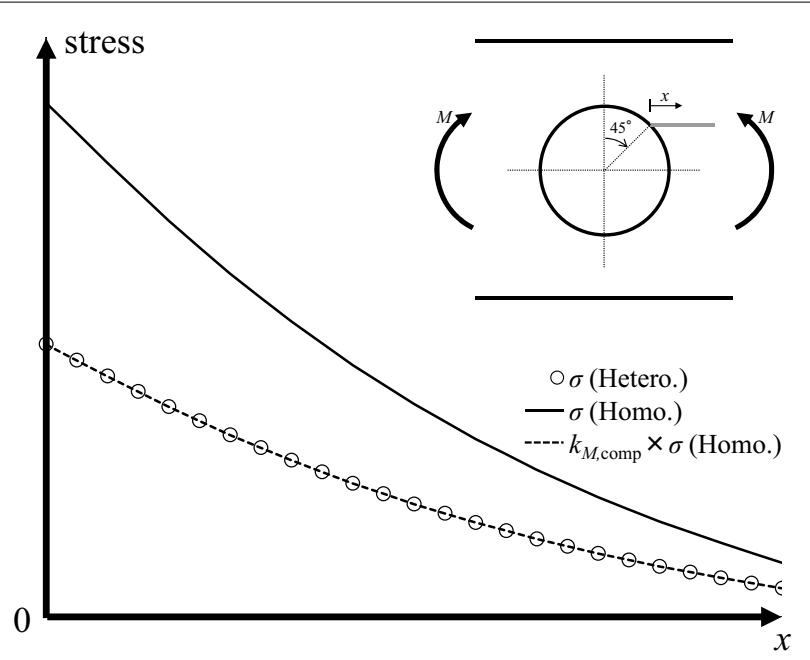

Pure bending moment

a Tensile stress distribution perpendicular to the grain

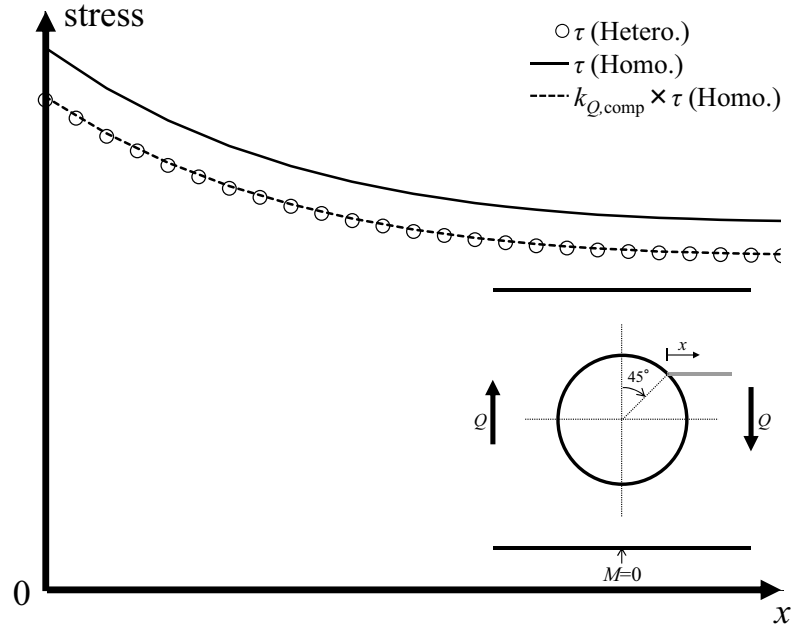

Pure shear force (center of hole)

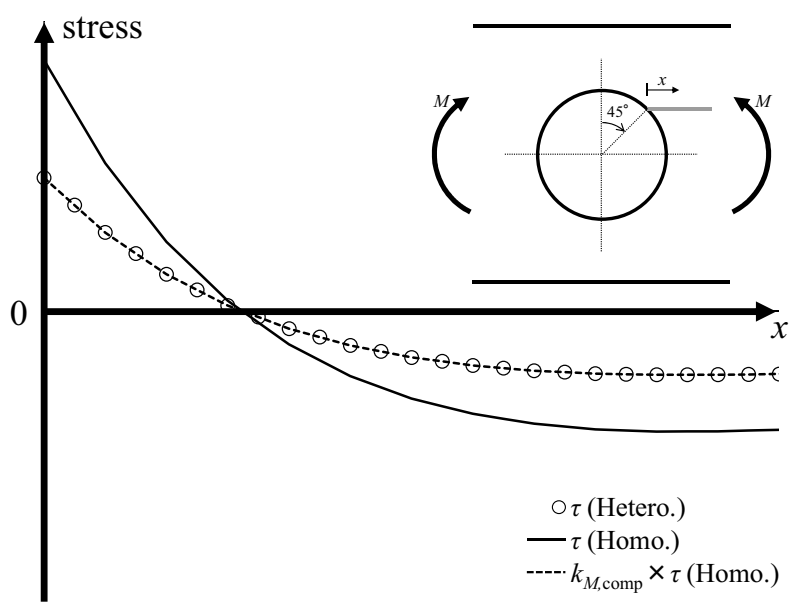

Pure bending moment

b Shear stress parallel to the grain

Fig. 16 Stress distribution in the direction parallel to the grain, Hetero. and Homo. [4]. a Tensile stress distribution perpendicular to the grain. b Shear stress parallel to the grain

$$
\begin{aligned}
& k_{Q, \mathrm{~ms}}=\frac{1}{1+1.8 \cdot x / D}, \\
& x=\frac{a_{\mathrm{ms}}}{1+\frac{a_{\mathrm{ms}}}{D}}, \\
& a_{\mathrm{ms}}=\frac{2}{\pi} \cdot \frac{G_{\mathrm{Ic}}}{F_{t 90}^{2}} \cdot \sqrt{\frac{2 \cdot E_{x} \cdot E_{y}}{\sqrt{\frac{E_{x}}{E_{y}}} \cdot \frac{E_{x}}{2 \cdot G_{x y}}-v_{x y} \cdot \frac{E_{x}}{E_{y}}}}
\end{aligned}
$$

$$
k_{M, \mathrm{~ms}}=1.6 \cdot k_{Q, \mathrm{~ms}}-0.6,
$$

where $D / H \leq 0.5 . A=1.025$ and $B=0.05$ for $F_{s} / F_{t 90}=3.0$. $A=1.02$ and $B=0.035$ for $F_{s} / F_{t 90}=3.5 . A=1.015$ and $B=0.025$ for $F_{s} / F_{t 90}=4.0 . k_{Q \text {, comp }}$ and $k_{M \text {, comp }}$ are 1.0 for GLT composed of homogeneous grade, and Table 3 gives the results for GLT composed of heterogeneous grade [4]. 


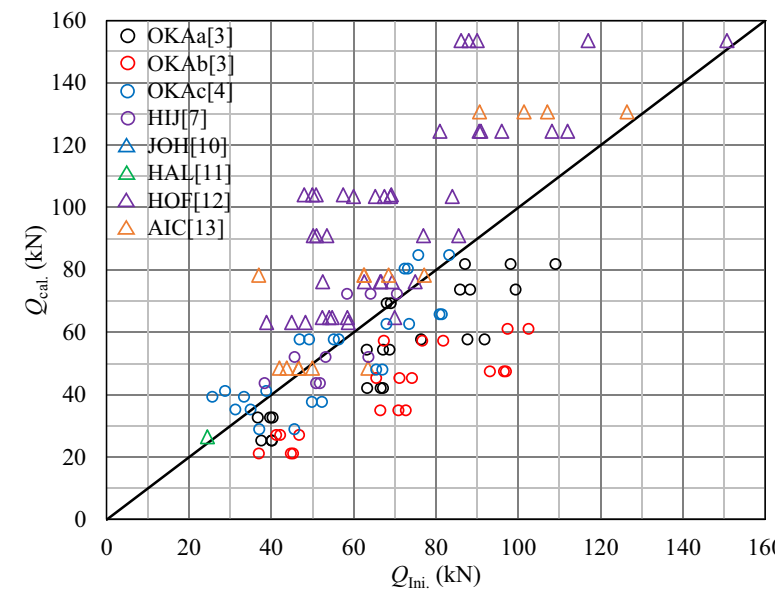

Relationship between $Q_{\mathrm{Ini}}$ and $Q_{\mathrm{Cal}}$.

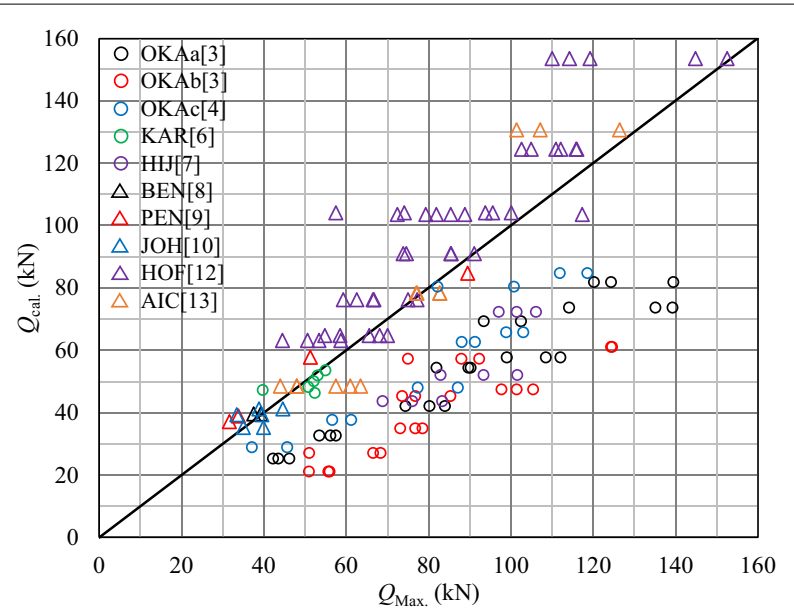

Relationship between $Q_{\text {Max. }}$ and $Q_{\text {Cal. }}$

Fig. 17 Checking the validity of Eq. (18)

\section{Validation of the formulas}

$E_{x}, E_{y}, G_{x y}, F_{s}, F_{t 90}$ and $G_{\mathrm{I} c}$ were obtained from the density $\rho$ of the existing experimental data [3, 4, 6-12] in Tables 1 and 2, and the splitting fracture load of GLT beams with a round hole was calculated from Eq. (18). A comparison of the experimental values of the initial crack load and maximum load with the calculated values of the splitting fracture load is shown in Fig. 17. The calculated values were compared with the experimental values of the GLT beams from Japan (Table 1), and for the initial crack load of the experimental values, OKAc [4] and HI [7] were approximately the same as the calculated values, but OKAa [3] and OKAb [3] were lower than the calculated values. For the maximum load of the experimental values, KAR [7] was approximately the same as the calculated value, but OKAa [3], OKAb [3], OKAc [4], and HIJ [7] were lower than the calculated values. The experimental and calculated values of GLT beams from countries other than Japan (Table 2) were compared, and the experimental values were approximately the same as the calculated values at the maximum load except for HOF [12]. However, some of the calculated values were slightly higher than the experimental values for the initial crack load. For HOF [12], the calculated value was higher, but the reason for this is not known.

For reference, we compared the calculated values of Eq. (18) with that of the existing design code for the experimental data shown in Tables 1 and 2. The existing design codes are the design method of the "end-notched beam analogy method" in Limträhandbok [5], the design method in DIN EN 1995-1-1/NA [25] and Limträhandbok [26], and the Weibull-based design proposal by Aicher and Höfflin [27]. The values of $F_{s}$ and $F_{t 90}$ used in the calculation of the existing design code are the same as those used in Fig. 17. Figure 18 shows a comparison of the calculated values. The calculated value of the existing design code is about 2.5 to 3.0 times higher than the calculated value of Eq. (18).

\section{Conclusion}

The tensile stresses perpendicular to the grain and shear stresses acting on the hole when a shear force or bending moment was applied to a GLT beam with a round hole are determined by FEA, and these stresses were formulated. Only the maximum stress acting on the hole was formulated, and a formula for calculating the splitting fracture capacity was proposed. Then, the validity of the proposed formula was verified using existing experimental data for GLT beams in Japan and outside Japan. As a result, it was confirmed that the proposed equation can estimate the fracture load for GLT beams of JAS [2] with a smaller value and that the proposed equation can estimate the fracture load for GLT beams from outside Japan with some accuracy except for a few cases. Since $F_{s}$ used in the practical design will be lower than $F_{s}$ used in this calculation, the proposed equation may have the potential to be used in the design of GLT beams of JAS [2] with a round hole. 


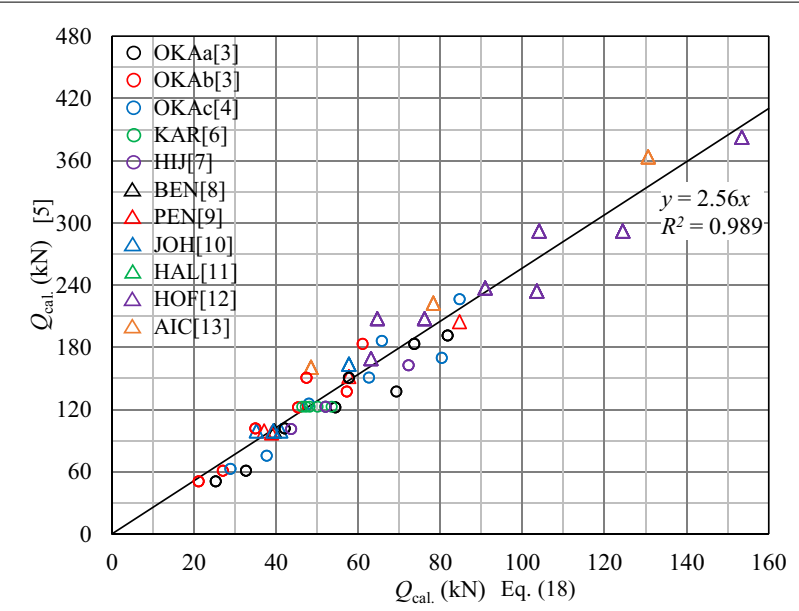

Eq. (18) and the existing design code [5]

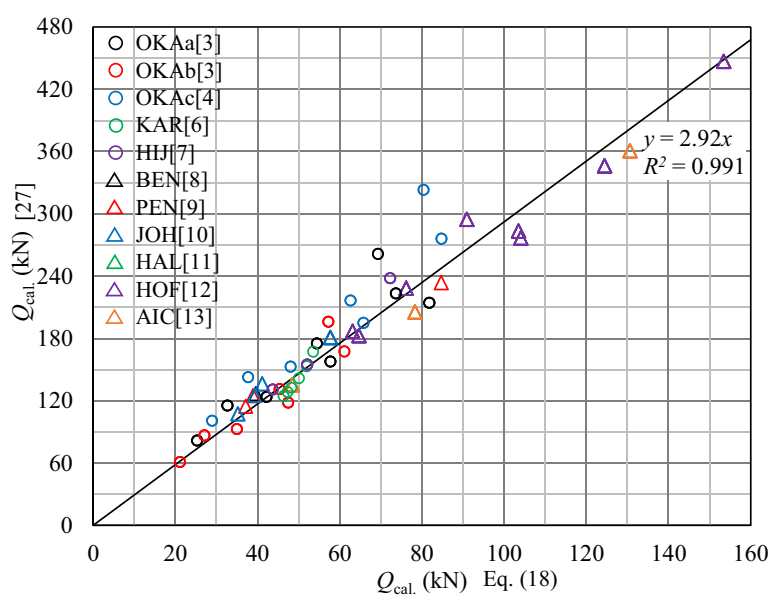

Eq. (18) and the existing design code [27]

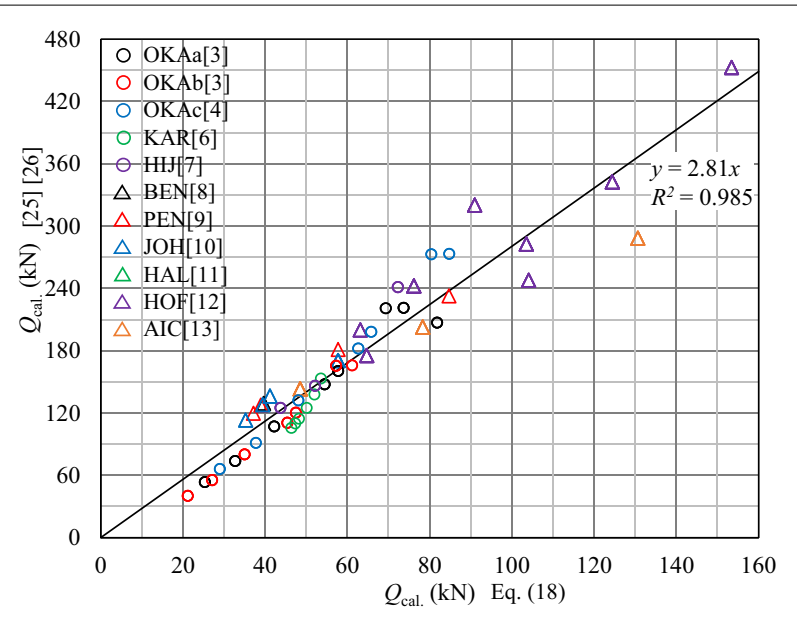

Eq. (18) and the existing design code [25] [26]

Fig. 18 Comparison of calculated values

\section{Abbreviations}

GLT: Glued laminated timber; JAS: Japanese Agricultural Standard; FEA: Finite element analysis; FE: Finite element; 2D-FEA: Two-dimensional finite element analysis.

\section{Supplementary Information}

The online version contains supplementary material available at https://doi. org/10.1186/s10086-022-02013-w.

Additional file 1: Figure S1. Mesh size of the FE model for the analysis around the hole. Figure S2. Mesh size of the FE model for the analysis of stress distribution in the direction parallel to the grain. Table $\mathbf{S 1}$. Coefficients of the polynomial (Eq. (8)) of $\sigma_{O^{\prime}} \sigma_{M}, \tau_{O}$ and $\tau_{M}$. Figure S3. Analysis results of the stress distribution. Table S2. Coefficients of the polynomial (Eq. (9)) of $\sigma_{Q}$ and $\sigma_{M}$. Table S3. Coefficients of the polynomial (Eq. (9)) of $\tau_{Q}$ and $\tau_{M}$. Figure $\mathbf{S} 4$. Relationship between the maximum value of $\sigma$ around the hole and $M /(Q H)$. $D / H=0.3$. Figure S5. Relationship between the average maximum value of $\bar{\sigma}$ around the hole and $x / D$. $D / H=0.3$. Figure S6. Comparison of the FEA results and calculated values (Eq. (15)) for $\bar{\sigma}_{\max } \cdot \bar{\sigma}_{\max }$ is the stress when $Q=\tau_{1} B H$ is acting. Figure
S7. Relationship between the average maximum value of $\bar{\sigma}$ incorporating the effect of the shear stress around the hole and $x / D$. $F_{s} / F_{t 90}=3.0$. $D / H=0.3$. Figure S8. Comparison of the FEA results and calculated values (Eq. $(15,17)$ ) for $k_{\tau} \bar{\sigma}_{\max } \cdot F_{s} / F_{t 90}=3.0 \cdot k_{\tau} \bar{\sigma}_{\max }$ is the stress when $Q=\tau_{1} B H$ is acting. Fig. S9: Comparison of the FEA results and calculated values (Eq. $(15,17)$ ) for $k_{\tau} \bar{\sigma}_{\max } \cdot F_{s} / F_{t 90}=3.5 \cdot k_{\tau} \bar{\sigma}_{\text {max }}$ is the stress when $\mathrm{Q}=\tau_{1} B \mathrm{H}$ is acting. Fig. S10: Comparison of the FEA results and calculated values (Eq. $(15,17)$ ) for $k_{\tau} \bar{\sigma}_{\max } \cdot F_{s} / F_{t 90}=4.0 \cdot k_{\tau} \bar{\sigma}_{\max }$ is the stress when $Q=\tau_{1} B H$ is acting.

\section{Acknowledgements}

We would like to thank American Journal Experts (https://www.aje.com/) for proofreading this manuscript.

\section{Authors' contributions}

SO planned and implemented the research and wrote the manuscript. All authors analyzed the results and read and approved the final manuscript.

\section{Funding}

This work was supported by JSPS KAKENHI (grant numbers 18K13867 and 20K04796). 
Availability of data and materials

The analysis method and data were recorded as shown in the manuscript. Additional data are available from the corresponding author upon reasonable request.

\section{Declarations}

\section{Competing interests}

The authors declare that they have no competing interests regarding the publication of this manuscript.

\section{Author details}

${ }_{1}^{1}$ Graduate School of Human Life Science, Osaka City University, 3-3-138 Sugimoto, Sumiyoshi-ku, Osaka 558-8585, Japan. ${ }^{2}$ National Institute for Land and Infrastructure Management, 1 Tachihara, Tsukuba 305-0802, Japan. ${ }^{3}$ Graduate School of Agricultural and Life Sciences, The University of Tokyo, 1-1-1 Yayoi, Bunkyo-ku, Tokyo 113-9657, Japan.

Received: 3 August 2021 Accepted: 14 January 2022

Published online: 27 January 2022

\section{References}

1. Aicher S, Gustafsson PJ, Haller P, Petersson H (2002) Fracture mechanics models for strength analysis of timber beams with a hole or a notcha report of RILEM TC-133. Report TVSM-7134, Division of Structural Mechanics, Lund University

2. Japanese Agricultural Standard (2007) JAS for Glued laminated timber. Japanese Agricultural Standards Association, Tokyo

3. Okamoto S, Araki Y, Akiyama N, Odani R, Aoki K, Inayama M (2020) Study on strength of glued laminated timber beams with round holes: estimation of splitting strength of glued laminated timber composed of heterogeneous grade by finite element analysis. J Struct Constr Eng Trans AlJ 85(775):1199-1208. https://doi.org/10.3130/aijs.85.1199

4. Okamoto S, Akiyama N, Araki Y, Aoki K, Inayama M (2021) Study on the strength of glued laminated timber beams with round holes: difference in structural performance between homogeneous-grade and heterogeneous-grade timber. J Wood Sci 67(8):1-25. https://doi.org/10 1186/s10086-021-01941-3

5. Carling O, Svenskt limträ $A B$ (2001) Limträhandbok (Glulam handbook). Print Media Center I Sundsvall AB, Stockholm

6. Karube M, Hayashi T, Harada M (2000) The strength of GLT beams with round utility holes. Summaries of Technical Papers of Annual Meeting Architectural Institute of Japan, Structures III, pp 225-226

7. Hijikata K, Idota H, Yamagishi K (2012) Proposal of design strength for glue-laminated timber beams with a circular through-hole. J Struc Constr Eng Trans AIJ 77(673):397-406. https://doi.org/10.3130/aijs.77.397

8. Bengtsson S, Dahl G (1971) Influence of holes near support on the strength of glulam beams. Dissertation, Lund University

9. Penttala V (1980) Glulam beams with holes. Publication 33, Division of Structural Engineering, Helsinki University of Technology

10. Johannesson B (1983) Design problems for glulam beams with holes. Dissertation, Chalmers University of Technology

11. Hallström S (1955) Glass fibre reinforced laminated timber beams with holes. Report 95-12, Department of Lightweight Structures, Royal Institute of Technology

12. Höfflin $L$ (2005) Round holes in glulam beams - experimental and theoretical analyses. Dissertation, University of Stuttgart

13. Aicher S, Höfflin L (2006) Load capacity and design of glulam beams with round holes-safety relevant modifications of design methods according to Eurocode 5 and DIN 1052. MPA Otto-Graf-Institute, University of Stuttgart

14. Danielsson H (2007) The strength of glulam beams with holes - a survey of tests and calculation methods. Report TVSM-3068, Division of Structural Mechanics, Lund University

15. Inc WSP (2019) Strength data and explanation of wood. Wood Structure Prom Inc, Tokyo

16. Kanaya N, Yamada T (1964) The relation between the elastic modulus and the porosity of wood. Wood Res 33:47-55
17. Forest Products Laboratory (2010) Wood handbook-wood as an engineering material. In: Kretschmann DE (ed) Mechanical properties of wood, Chapter 5. General Technical Report FPL-GTR-190 United States. Department of Agriculture Forest Service, Madison

18. Forestry and Forest Products Research Institute (2004) Wood industry handbook. Maruzen, Tokyo

19. Kitahara K (1966) Wood physics. Morikitashuppan, Tokyo

20. Architectural Institute of Japan (2006) Standard for structural design of timber structures. Maruzen, Tokyo

21. . Iwasaki K, Yasumura M (2005) Estimating fracture strength of bolted timber joints loaded perpendicular to wooden grain-proposal for fracture parameter. Summaries of Technical Papers of Annual Meeting, Architectural Institute of Japan, Structures III, pp 273-274

22. Okamoto S, Akiyama N, Nakamura N, Aoki K, Inayama M (2021) Estimation of the tension perpendicular to the grain strength of glued laminated timber of Scots pine via three-point bending tests. J Wood Sci 67(33):1-11. https://doi.org/10.1186/s10086-021-01966-8

23. Larsen HJ, Gustafsson PJ (1990) The fracture energy of wood in tension perpendicular to the grain-results from a joint testing project. In: Proceedings of the CIB-W18A meeting 23, Paper 23-19-2, LNEC, Lisbon, 10-14 September 1990

24. Okamoto S, Nakatani M, Akiyama N, Tanaka K, Mori T (2021) Verification of shear performance of mortise and tenon joint with top and bottom notches at the beam end. J Wood Sci 67(47):1-23. https://doi.org/10. 1186/s10086-021-01979-3

25. DIN EN 1995-1-1/NA (2010) National Annex-Nationally determined parameters - Eurocode 5: design of timber structures-Part 1-1: general-common rules and rules for buildings. DIN, Berlin.

26. Fröbel J (2016) Limträhandbok Del 2. Svenskt Trä, Stockholm

27. Aicher S, Höfflin L, Reinhardt HW (2007) Runde Durchbrüche in Biegeträgern aus Brettschichtholz-Teil 2: Tragfähigkeit und Bemessung. Bautechnik 84(12):867-880. https://doi.org/10.1002/bate.200710074

\section{Publisher's Note}

Springer Nature remains neutral with regard to jurisdictional claims in published maps and institutional affiliations.

\section{Submit your manuscript to a SpringerOpen ${ }^{\circ}$ journal and benefit from:}

- Convenient online submission

- Rigorous peer review

- Open access: articles freely available online

- High visibility within the field

Retaining the copyright to your article

Submit your next manuscript at $\boldsymbol{\nabla}$ springeropen.com 